Research Article

\title{
Mechanical and Coal Burst Breeding Mechanism of Coal Samples under True Triaxial Loading and Unloading
}

\author{
Wei Shen $(\mathbb{D})^{1,2}$ Lin-ming Dou $\mathbb{D}^{2}{ }^{2}$ and $\mathrm{Hu} \mathrm{He}^{3}$ \\ ${ }^{1}$ Faculty of Architecture and Civil Engineering, Huaiyin Institute of Technology, Huai'an, Jiangsu 223001, China \\ ${ }^{2}$ School of Mines, Key Laboratory of Deep Coal Resource Mining, Ministry of Education, \\ China University of Mining and Technology, Xuzhou, Jiangsu 221116, China \\ ${ }^{3}$ School of Resources and Earth Science, China University of Mining and Technology, Xuzhou, Jiangsu 221116, China \\ Correspondence should be addressed to Lin-ming Dou; lmdou@126.com
}

Received 6 April 2019; Revised 16 July 2019; Accepted 14 August 2019; Published 11 November 2019

Academic Editor: Zaobao Liu

Copyright (C) 2019 Wei Shen et al. This is an open access article distributed under the Creative Commons Attribution License, which permits unrestricted use, distribution, and reproduction in any medium, provided the original work is properly cited.

\begin{abstract}
A true triaxial loading and unloading experiment entailing " $y$-direction stress loading, $z$-direction stress unloading, and $x$ direction displacement fixing" of coal samples was conducted. Through analysis of the stress characteristics, fracture characteristics, and energy evolution in coal samples, the mechanical and coal burst breeding mechanisms of coal samples under true triaxial loading and unloading were revealed. The experiment found that the yield stress and peak stress of coal samples were not only affected by the initial loading and unloading of lateral stress but also had a negative exponential relationship with the ratio of the unloading rate and the loading rate (RURLR), thereby establishing the stress equation of coal samples under a true triaxial loading and unloading. There was a yield turning point in the stress-time curve of coal samples, and the difference in triaxial stress and acoustic emission before, and after, yield was significant. It was found that a high unloading rate and high initial stress are precursors to coal sample bursting. During loading and unloading, the high-energy area expanded, but its location was always fixed to within a certain area. The energy in this area was rapidly released to form a burst source when the sample was subjected to high-speed unloading. The nonbursting coal samples and the burst coal samples showed characteristic slabbing and bursting behaviours, respectively: the former corresponding to the acoustic emission energy value being two orders of magnitude lower than the latter. The research results can provide a reference for the study of mechanical behaviours and coal burst criteria in the rock surrounding a coal roadway excavation.
\end{abstract}

\section{Introduction}

Coal bursting, a typical coal-rock dynamic disaster, occurs frequently during excavation and threatens the safety of workers [1-3].

Mine research institutions and coal mine enterprises have always considered overlying strata movement as an important influencing factor in inducing coal bursts [4-7], whereas coal roadway excavation is basically unaffected by overlying strata. Therefore, the original coal burst mechanism, evaluation methods, and prevention theory based on overlying strata movement are not particularly applicable. Before the excavation of a solid coal roadway, the rock masses at depth exist in a true triaxial equilibrium state.
After the excavation of a solid coal roadway, the radial stress on the rock surrounding that roadway is subjected to unloading effects; tangential stress undergoes the greatest loading effect, the axial direction is constrained by the adjacent coal body, and the displacement remains almost unchanged. The surrounding rock of driving roadway shows the stress path "the radial-direction unloading, tangentialdirection loading, and axial-direction fixing." The radial stress on the free face is relieved completely, and with the increase in the distance away from free face, the unloading effect weakens gradually, resulting in the increase of radial stress to a true triaxial equilibrium state. The tangential stress is at a lower level due to the relatively fragmented coal body close to the free face. The tangential stress reaches its 
maximum at a certain distance from the free face and then decreases gradually with the increase in the distance away from the free face until it stabilizes to the true triaxial equilibrium state. According to other research $[8,9]$, the stress on the coal body is adjusted along different stressstrain paths after excavation. This path has an important effect on stress, elasto-plastic variation, and fracturing of coal samples. Starting from the stress path in surrounding rock in a solid coal roadway excavation, we study the deformation, fracture, and burst characteristics of a coal body under true triaxial loading and unloading stress paths by means of experiments. The results can provide a reference for the interpretation of coal burst mechanisms in solid coal roadway excavations.

Researchers have studied the stress-strain characteristics and rock burst formation characteristics of specimens under triaxial loading-unloading. For example, Wang et al. [10] found that some indexes to denote mechanical behaviours of rocks, such as triaxial compressive strength, angle of internal friction, and angle of shearing resistance, obtained from the unloading triaxial tests are greater than those of the conventional triaxial tests. Chen et al. [11] found that all failures under confining pressure unloading conditions featured brittle shear failure with a single macro shear rupture surface under confining pressure unloading conditions. Dai et al. [12] found that specimens under pure loading failed with a single distinct shear fracture, while for the unloading case, specimens displayed multiple intersecting fractures. Huang et al. [13] found there are many tension cracks in various grades of the damaged rock, and the tension crack surface is generally perpendicular to the main unloading direction in unloading experiments. Su et al. [14] carried out the experiments with a loading path that maintained one free face and applied loading along three axial directions on the other five faces and found that the tunnel axis stress has a significant influence on the strain burst characteristics. Qiu et al. [15] carried out the true triaxial loading-unloading experiments and found rock mass slabbing induced by high rock stress has major impacts on the evolution and formation of buckling rock burst in deep tunnels. In the true triaxial loading-unloading experiment, $\mathrm{Li}$ et al. [16] found the total strain energy, elastic strain energy, and circumferential strain energy all increase as the initial confining pressure increases, whereas the dissipative strain energy does not. Guo et al. [17] found that axial and radial strains increase sharply with decreasing confining pressure in the initial stage of unloading. An obvious radial expansion has also been shown during unloading confining pressure. Su et al. [18] used an improved true triaxial test machine to simulate remotely triggered rock burst induced by a tunnel axial dynamic disturbance. Through experiments, they found that the static stresses acting on the rock mass in three directions have different effects on rock burst, and rock burst can be triggered more easily with increasing amplitude or frequency. Yin et al. [19] found the true-triaxial loadingunloading stress path has a great influence on the deformation and failure behaviour, strength characteristics, and permeability evolution in the experiment. Chen et al. [20] carried out an experiment with one face kept free and the other five faces loaded and found that rock burst occurrence depends on several conditions, including specifically the tangential loading rate exceeding a certain threshold, the presence of considerable amounts of stored strain energy, the dissipation of energy through rock splitting on the free face, and the shear failure in the potential rock burst pit. Feng et al. [21] found that the peak strength is nonsymmetrical with the increasing $\sigma 2$ and is closely related to the lode angle, and the strength variation exhibited a close relationship to the failure mechanism. Liu et al. [22] found that pre-existing flow planes play significant roles in the strength levels, failure modes, and permeability levels under true-triaxial stress paths. Zhu et al. [23] found that bursting failure occurs when the axial stress is more than three times the uniaxial compressive strength of the coal sample under a constant confining pressure.

Numerous studies [24-28] have been conducted to obtain a comprehensive understanding of coal and rock failure via the application of AE monitoring techniques. At present, AE studies of rock failures under true triaxial unloading conditions have gained attention. According to the true triaxial unloading tests, the AE hit rate is evidently enhanced when the least principal stress is unloaded, and the range of the $\mathrm{AE}$ count rate increases with the intermediate principal stress [29]. He et al. [30-32] studied the mechanism of rock burst in deep-buried tunnel by a true-triaxial experiment and revealed the characteristics of acoustic emission energy. Zhao et al. [33] found that the rock samples are prone to strain burst failure under a high unloading rate, and the associated acoustic emission energy release in the strain burst process is dependent on the unloading rate. Su et al. [34] performed rock burst tests on granite rock specimens under true triaxial loading conditions and found that the evolutionary features of sound signals on the eve of rock burst, as well as that of AE signals, can be used as beneficial information for rock burst prediction. Bai et al. [35] conducted a true triaxial acoustic emission (AE) experiment to simulate excavation-induced damage by applying in situ 3D stress path to a sample. Through experiments, they found that stress unloading plays an important role in $\mathrm{AE}$ activity. Characteristics of $\mathrm{AE}$ events exhibit a good agreement with the microseismicity recorded in the tunnel roof, and source parameters (e.g., corner frequency and moment magnitude) are consistent with the field recordings.

According to the previous study of the triaxial loading and unloading, the fixed displacement of one axis and the effect of loading and unloading rate and ratio were not considered; the critical burst criterion for coal samples, the difference in fracture characteristics between the burst coal samples and nonburst coal samples, and the process of coal sample energy accumulation and coal burst generation were not given: these are claimed as innovative herein.

\section{Experimental Work}

2.1. Experimental Apparatus. The polar coordinate system and rectangular coordinate system can be transformed into each other, so the stress path " $y$-direction stress loading, 
$z$-direction stress unloading, and $x$-direction displacement fixing"(rectangular coordinate system) can be used to express the surrounding rock path "the radial-direction unloading, tangential-direction loading, the axial-direction fixing" (polar coordinate system). The " $y$-direction stress loading, $z$-direction stress unloading, and $x$-direction displacement fixing" triaxial loading and unloading experimental equipment is shown in Figure 1(a): the waveform delineating the coal fracture event was monitored by an American Physical Acoustics PCI-2 acoustic emission acquisition system, using eight Micro-80S miniature $\mathrm{AE}$ probes, which were embedded in the iron block (Figure 1(b)). The surfaces of the probes were coated with Vaseline to achieve close integration with the coal samples; a layer of rubber was placed between the fixture iron block and the coal block to prevent the wave propagating through the iron block to the probes, thereby improving the accuracy of waveform signal monitoring.

2.2. Test Procedure. The coal samples used in this experiment were from the No. 5 coal seam of Huating Coal Mine. The coal samples measured $70 \times 70 \times 70 \mathrm{~mm}$, and the flatness error was less than $1 \mathrm{~mm}$. Some basic material properties of the coal samples are shown in Table 1. According to He [36], the strain rate of coal samples in static loading and unloading should be controlled to within $10^{-3} \cdot \mathrm{s}^{-1}$. According to this, the three-directional loading and unloading rate of experiments was controlled to within $4.2 \mathrm{~mm} / \mathrm{min}$.

Three types of experiments were designed: (1) Effect of RURLRs: the three-directional stresses on the sample were loaded to a specified initial stress of $20 \mathrm{MPa}$, and then the $y$ axis and $z$-axis were loaded and unloaded at a certain rate, respectively. The unloading rate in the $z$-direction is 0.3 to 3.5 times than that on the $y$-axis, and the displacement along the $x$-axis remains unchanged. (2) Effect of triaxial initial stress: the $x$-, $y$-, and $z$-axes were respectively loaded to different initial stresses (Table 2), and then stress path experiments were carried out according to a certain RURLR (Table 2), during which the displacement along the $x$-axis remained unchanged. (3) Burst experiment: at the end of scheme (1) or scheme (2), the unloading rates along the $z$ axis of some samples are increased between five- and 10-fold, while other parameters remained unchanged.

\section{Experimental Results and Analysis}

3.1. Prepeak Characteristics of Curves under True Triaxial Stress Paths. Because of space limitations, only typical triaxial stress-time curves of coal samples are shown in Figure 2. According to the graph, the prepeak stress curves under different initial stresses (Figures 2(a)-2(d)) and different RURLRs (Figures 2(a) and 2(e)) could be divided into two distinct stages, as described below.

Stage (I): because of unloading along the $Z$-axis, the stress in this direction decreased gradually; however, unloading here does not affect the increase in $Y$-axis stress (the loaded side), and the stress on the loaded side increased in a quasi-linear manner. According to $\mathrm{AE}$ event counts, the energy and frequency of AE events in this stage were low, which indicated that there was no large area of cracking in the coal samples in this stage, and the coal samples were relatively complete and in an elastic state.

Stage (II): when the triaxial stress reached a certain value, the $Y$-and $Z$-axial stress-time curves show a significant inflection point (point A, Figure 2), which was called the yield point. The AE event counts were significantly enhanced, which meant that cracks in the coal samples began to develop. At this stage, the rate of increase of $Y$-axial stress was significantly smaller than in Stage I, exhibiting plastic yield characteristics. The $Z$-axis stress variations were affected by the RURLRs: according to statistical results, when the RURLRs are less than 0.8 , the $Z$ stress showed an increasing trend in Figures 2(a)2 (c). This is because volumetric expansion during coal failure is greater than that in a coal body upon unloading and then the coal body is compressed. When the RURLRs are greater than 0.8 , the $Z$-stress showed a tendency to slowly decrease or change (Figures 2(d) and 2(e)) because the volumetric expansion at failure is less than that upon unloading and then the coal body is subjected to outward tensile action.

During the whole true-triaxial loading and unloading test, the fixed-side ( $X$-axis) stress variation is small and shows only slight increases or decreases.

3.2. Coal Sample Burst Conditions under a True-Triaxial Stress Path. After the completion of the scheme (1) or scheme (2) on the samples $M \backslash N \backslash O \backslash P \backslash Q \backslash R$, the unloading rates along the $z$-axis of some samples are increased between five- and 10-fold, as shown in Figure 3. The experiments at this stage are called burst experiments. The major principal stress-time curves and $\mathrm{AE}$ energy-time curves of coal samples in the burst experiment are shown in Figure 3.

Through the literature review, it was found that a coal burst is an engineering term, and there is no definition for a coal sample burst in laboratory experimental terms: herein, coal sample bursting in our experiment is defined by analogy to characteristics of coal bursts in mines.

Coal bursts generally have three distinctive features: (1) When a coal burst occurs, sound and vibration are generated. (2) The energy released by a tremor, as monitored by microseismic equipment, is generally over $1 \times 10^{4} \mathrm{~J}$. (3) The destruction of a coal mass releases elastic energy, and the rocks surrounding a roadway gain kinetic energy. By analogy with a coal burst to a coal mine, the experimental coal samples could be defined as having burst if they satisfied the following three conditions: (1) When the coal sample breaks down, there is significant sound and vibration. (2) The fracture energy of acoustic emission events is greater than $1.0 \times 10^{7} \mu \mathrm{V} \cdot \mathrm{s}$; (3) The stress-strain curve of coal sample exhibits a sudden stress drop, which represents the release of elastic energy. 


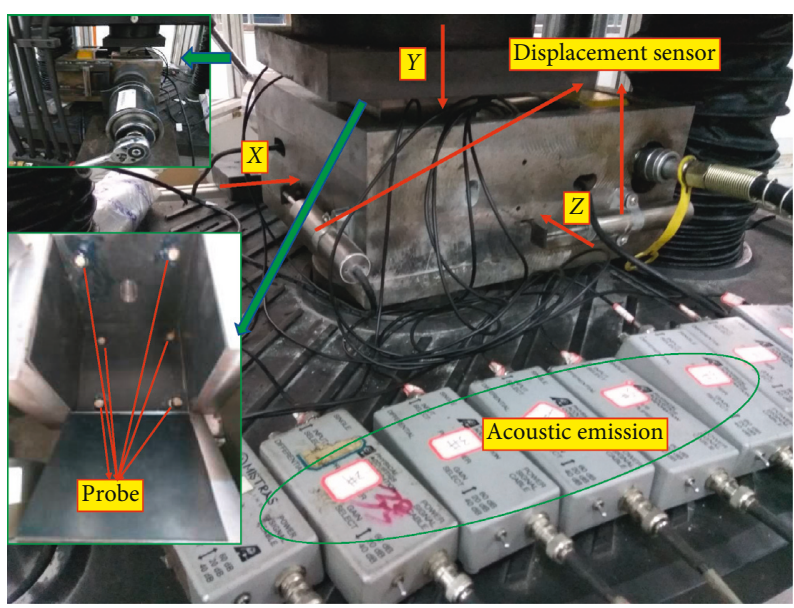

(a)
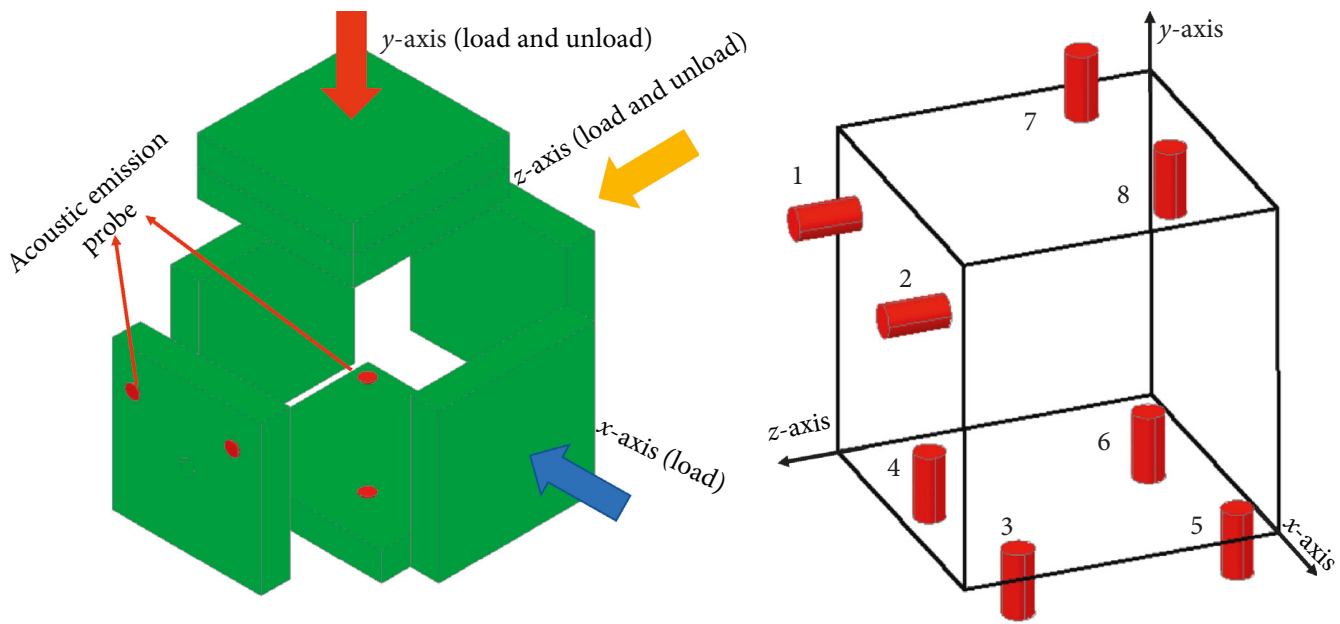

(b)

Figure 1: Experimental system. (a) Experimental apparatus. (b) Layout of the triaxial clamps and acoustic emission probes.

TABLE 1: Basic properties of the tested material.

\begin{tabular}{lc}
\hline Property & Mean value \\
\hline Longitudinal wave velocity & $1200 \mathrm{~m} / \mathrm{s}$ \\
Density & $1400 \mathrm{~kg} / \mathrm{m}^{3}$ \\
Compressive strength & $8 \mathrm{MPa}$ \\
Elastic modulus & $0.85 \mathrm{GPa}$ \\
\hline
\end{tabular}

In scheme (1) or scheme (2), the unloading rates of samples $\mathrm{M}, \mathrm{Q}$, and $\mathrm{R}$ are less than $1.13 \mathrm{~mm} / \mathrm{min}$ (Table 2). At this time, there is no significant sound emitted when the sample is destroyed, the AE energy is less than $1.0 \times 10^{7} \mu \mathrm{V} \cdot \mathrm{s}$, and the stress does not suddenly drop, which means that the coal sample had not burst. When the unloading rates are greater than $2.77 \mathrm{~mm} / \mathrm{min}$, samples $\mathrm{M}$, $\mathrm{Q}$, and $\mathrm{R}$ showed signs of a coal sample burst, as shown in Figures 3(a), 3(e), and 3(f): the high unloading rate is thus deemed to be an important factor influencing coal sample bursting.

During the burst experiment, coal samples $\mathrm{M}, \mathrm{Q}$, and R with high initial stress (initial triaxial stress greater than $60 \mathrm{MPa}, 23.96 \mathrm{MPa}$, and $9.02 \mathrm{MPa}$, respectively) exhibited bursting behaviours, as shown in Figures 3(a), 3(e), and 3(f), while coal samples $\mathrm{N}$ and $\mathrm{O}$, under low initial stress (less than $61.93 \mathrm{MPa}, 22.96 \mathrm{MPa}$, and $10.16 \mathrm{MPa}$, respectively), did not exhibit bursting behaviours, as shown in Figures 3(b) and 3(c): the high initial stress is another factor influencing coal sample bursting. According to the experiment, the high unloading rate and a high initial stress are precursors for a coal sample burst.

3.3. The Characteristics of Failure and AE Events. According to the experimental statistics, failure types of coal samples can be divided into two categories: bursting and nonbursting. The nonbursting type represented by coal sample $\mathrm{C}$ and the bursting type represented by coal sample $\mathrm{M}$ were selected, respectively. As shown in Figure 4, planes 1 and 3 are parallel to the unloading surface, and planes 2, 4, 5, and 6 are perpendicular to the unloading surface. Figures 5(a) and 5(b) correspond to the AE event distribution maps of samples $\mathrm{C}$ and $\mathrm{M}$, respectively, during testing (because of the large number of AE events, only energy levels greater than $1.0 \times 10^{3} \mu \mathrm{V} \cdot \mathrm{s}$ are listed).

According to the photographs of coal sample $\mathrm{C}$ in Figure 4(a), the nonbursting coal sample mainly suffers 
Table 2: Experimental conditions.

\begin{tabular}{|c|c|c|c|c|c|}
\hline Influencing factor & $\begin{array}{c}\text { Coal sample } \\
\text { number }\end{array}$ & $\begin{array}{c}X / Y / Z \text { axial stress/ } \\
\mathrm{MPa}\end{array}$ & $\begin{array}{l}\text { Unloading rate } \\
\left(\mathrm{mm} \cdot \mathrm{min}^{-1}\right)\end{array}$ & $\begin{array}{l}\text { Loading rate } \\
\left(\mathrm{mm} \cdot \mathrm{min}^{-1}\right)\end{array}$ & RURLR \\
\hline \multirow{11}{*}{ RURLR } & $\mathrm{G}$ & $20 / 20 / 20$ & 0.56 & 1.5 & 0.4 \\
\hline & I & $20 / 20 / 20$ & 0.97 & 2 & 0.5 \\
\hline & $\mathrm{H}$ & $20 / 20 / 20$ & 0.84 & 1.5 & 0.6 \\
\hline & $\mathrm{K}$ & $20 / 20 / 20$ & 1.09 & 2 & 0.5 \\
\hline & $\mathrm{L}$ & $20 / 20 / 20$ & 1.18 & 1.5 & 0.8 \\
\hline & $\mathrm{J}$ & $20 / 20 / 20$ & 0.98 & 1 & 1.0 \\
\hline & $\mathrm{B}$ & $20 / 20 / 20$ & 1.08 & 1 & 1.1 \\
\hline & $\mathrm{A}$ & $20 / 20 / 20$ & 0.77 & 0.5 & 1.5 \\
\hline & $\mathrm{C}$ & $20 / 20 / 20$ & 0.85 & 0.5 & 1.7 \\
\hline & $\mathrm{D}$ & $20 / 20 / 20$ & 0.72 & 0.25 & 2.9 \\
\hline & $\mathrm{E}$ & $20 / 20 / 20$ & 0.80 & 0.25 & 3.2 \\
\hline \multirow{3}{*}{ Initial loading lateral stress } & $\mathrm{O}$ & $20 / 10 / 20$ & 0.83 & 1.5 & 0.6 \\
\hline & $\mathrm{H}$ & $20 / 20 / 20$ & 0.84 & 1.5 & 0.6 \\
\hline & $\mathrm{P}$ & $20 / 40 / 20$ & 0.84 & 1.5 & 0.6 \\
\hline \multirow{3}{*}{$\begin{array}{l}\text { Initial unloading lateral } \\
\text { stress }\end{array}$} & $\mathrm{F}$ & $20 / 20 / 10$ & 0.83 & 1.5 & 0.6 \\
\hline & $\mathrm{H}$ & $20 / 20 / 20$ & 0.84 & 1.5 & 0.6 \\
\hline & Q & $20 / 20 / 40$ & 0.83 & 1.5 & 0.6 \\
\hline \multirow{3}{*}{ Initial fixed lateral stress } & $\mathrm{S}$ & $10 / 20 / 20$ & 1.15 & 1.5 & 0.8 \\
\hline & $\mathrm{L}$ & $20 / 20 / 20$ & 1.18 & 1.5 & 0.8 \\
\hline & $\mathrm{R}$ & $40 / 20 / 20$ & 1.13 & 1.5 & 0.8 \\
\hline
\end{tabular}

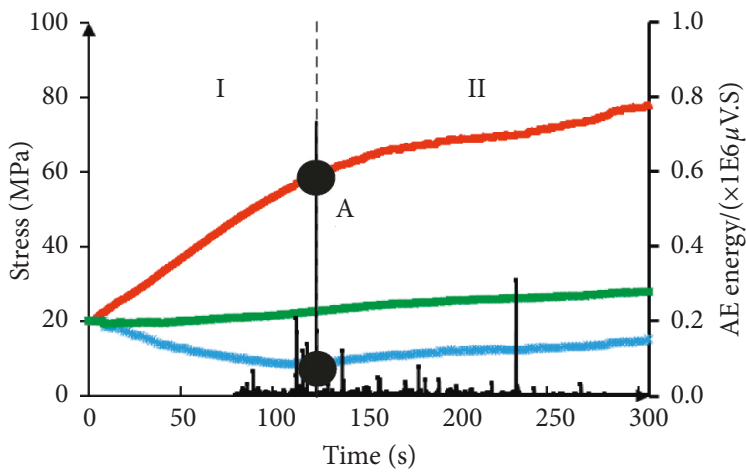

$-Y$-axis
$-Z$-axis

$\rightarrow X$-axis

$\longrightarrow$ AE energy

(a)

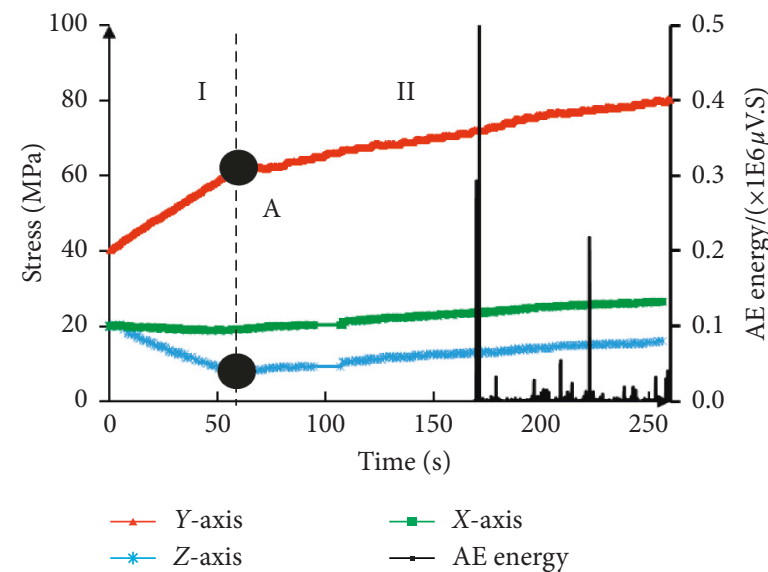

(c)

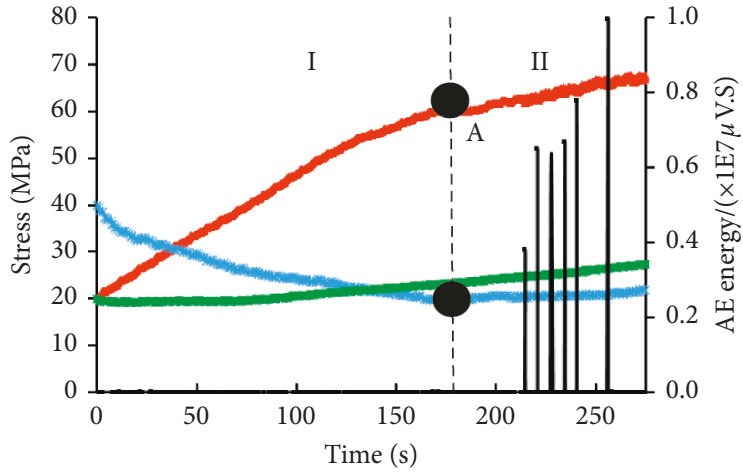

$\longrightarrow Y$-axis

$\rightarrow X$-axis

* $Z$-axis

(b)

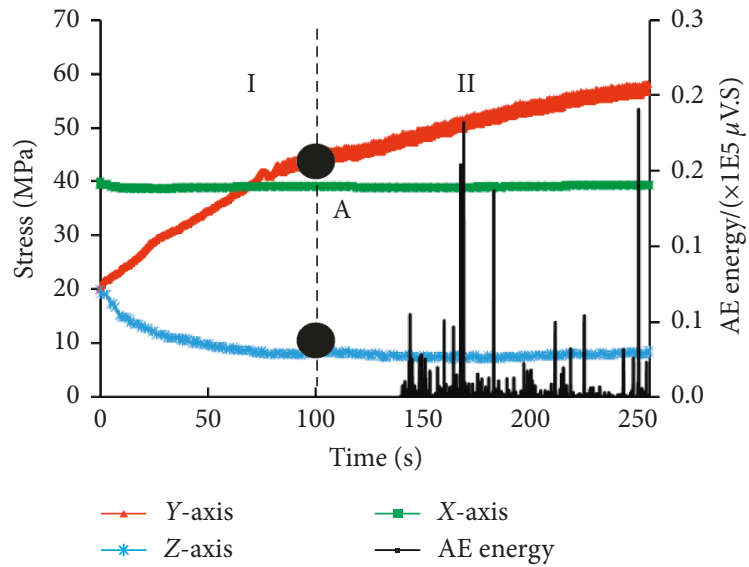

(d)

FIgURE 2: Continued. 


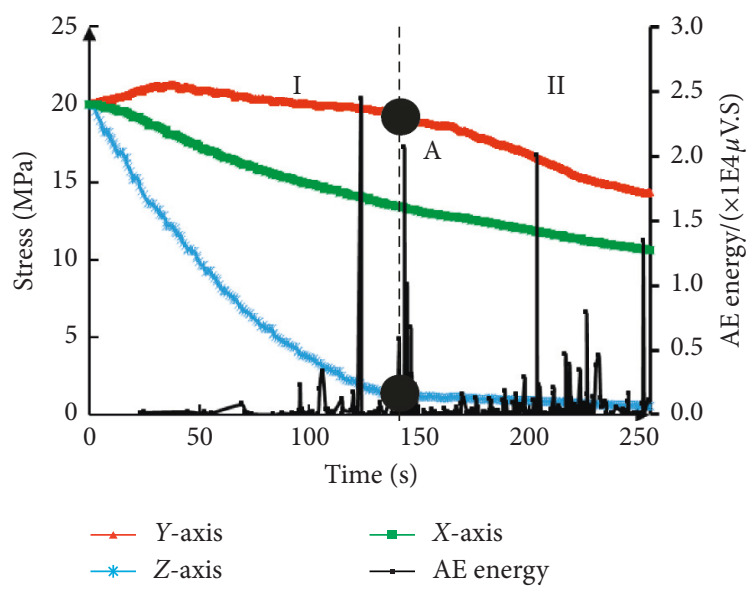

(e)

FIGURE 2: Triaxial stress-time curves of coal samples and acoustic emission-time curves. (a) Initial isobaric pressure (RURLR of 0.6). (b) High initial unloading lateral stress (RURLR of 0.6). (c) High initial stress of loading lateral (RURLR of 0.6) (d) High initial stress of fixing lateral (RURLR of 0.8). (e) High RURLR (2.9).

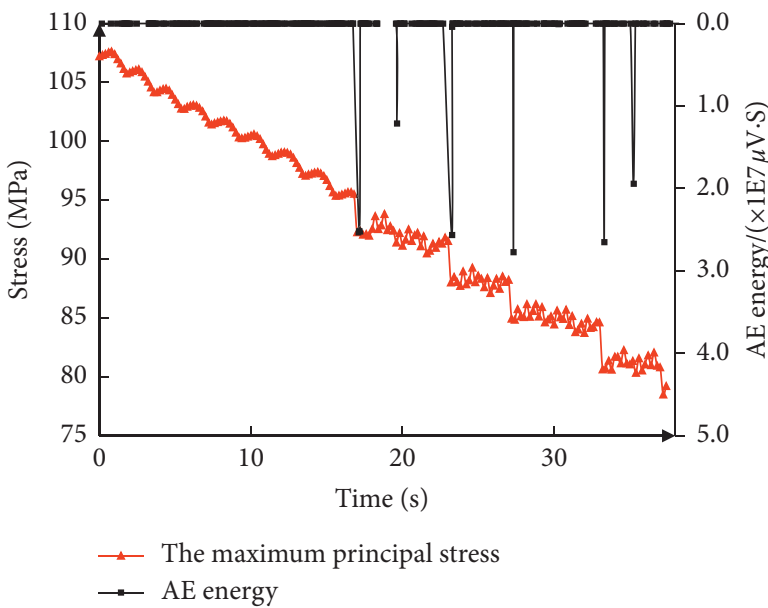

(a)

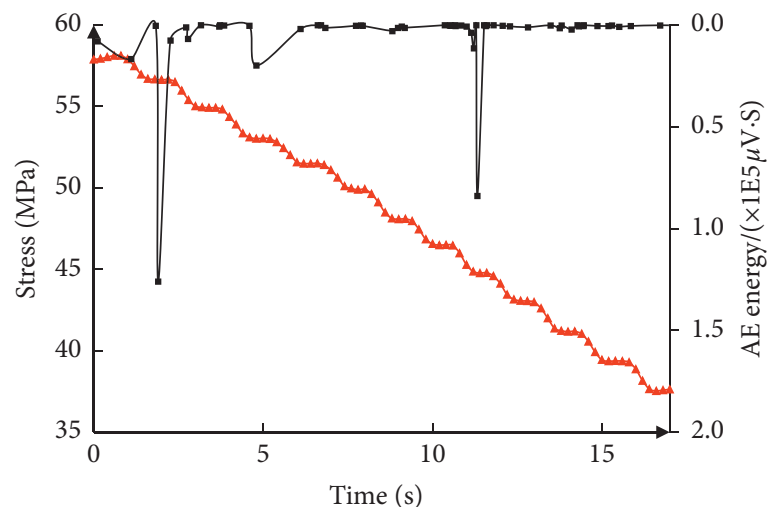

$\simeq$ The maximum principal stress

$\rightarrow$ AE energy

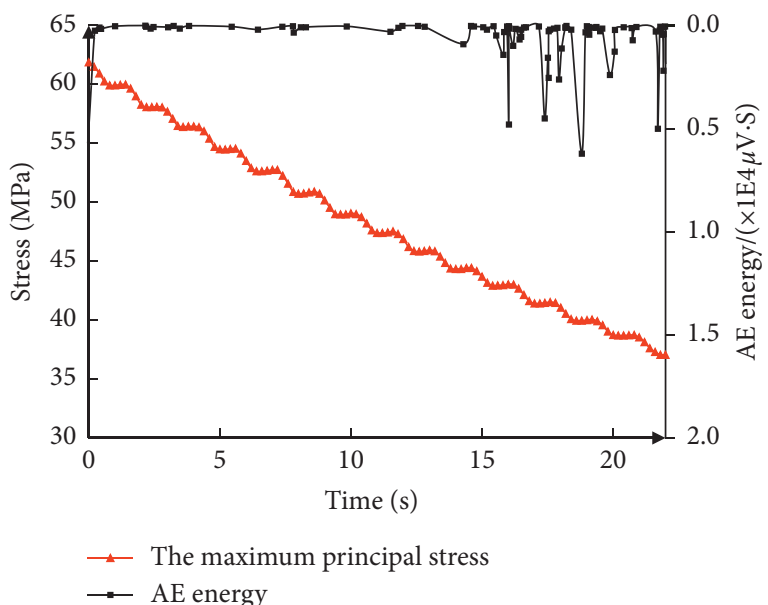

(b)

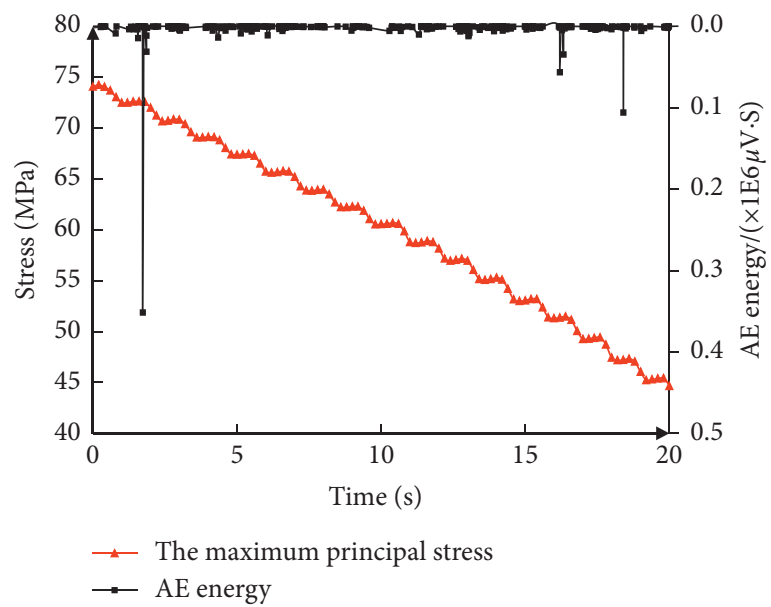

(d)

Figure 3: Continued. 


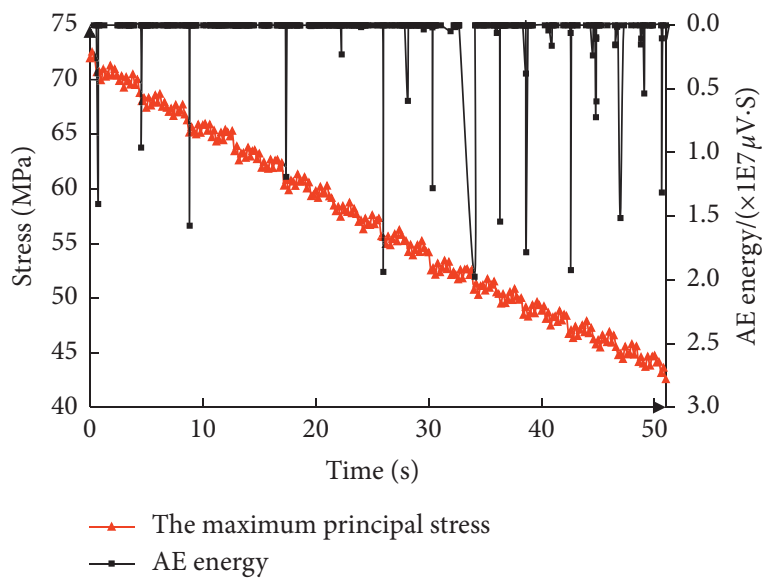

(e)

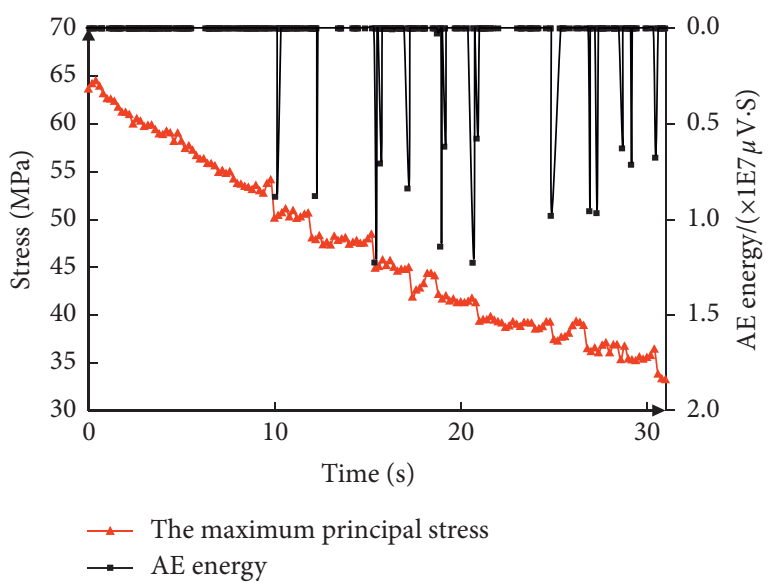

(f)

Figure 3: The major principal stress-time and AE energy-time curves of coal samples. (a) Sample M (rate: $2.77 \mathrm{~mm} / \mathrm{min}$ ). (b) Sample N (rate: $6.12 \mathrm{~mm} / \mathrm{min}$ ). (c) Sample O (rate: $4.26 \mathrm{~mm} / \mathrm{min}$ ); (d) Sample P (data loss). (e) Sample Q (rate: $3.86 \mathrm{~mm} / \mathrm{min}$ ); (f) Sample R (rate: $4.78 \mathrm{~mm} / \mathrm{min}$ ).

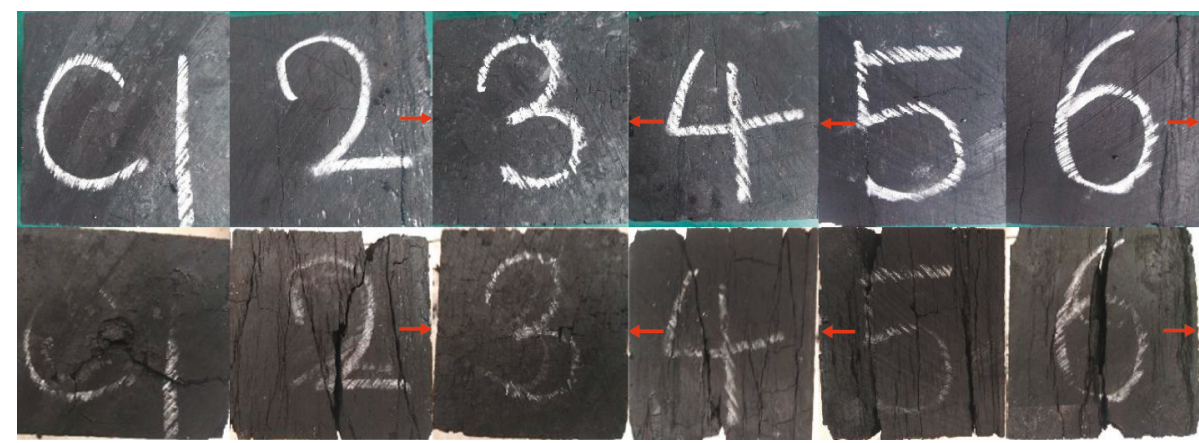

(a)

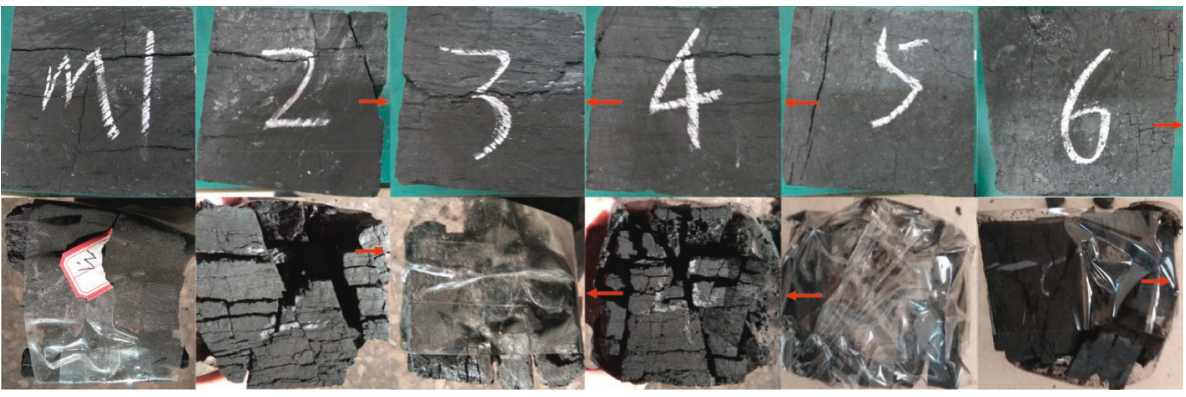

(b)

FIGURE 4: Comparison of nonbursting sample and bursting sample before and after testing (previous row: pretest photos; next row: post-test photos; The red arrow: the direction of unloading): (a) nonbursting coal sample (sample C); (b) bursting coal sample (sample M).

spallation failure, and the normal direction of the failure surface is parallel to the direction of unloading. This is because the coal sample is initially in a three-directional compressive stress state, and when unloading is carried out in one direction, a tensile stress perpendicular to the unloading surface will, thus, be formed. When the tensile force is greater than the tensile strength of the coal samples, a series of cracks parallel to the unloading surface are formed. Since the rate of unloading is low, the coal samples had sufficient time to form through-cracks on the 2, 4, 5, and 6 planes, as shown in Figure 4(a). The tensile stress at failure is low and the energy released is relatively small. The energy of acoustic emission events is less than $1.0 \times 10^{5} \mu \mathrm{V} \cdot \mathrm{s}$ and mainly less than $1.0 \times 10^{3} \mu \mathrm{V} \cdot \mathrm{s}$, as shown in Figure 5(a).

According to the photographs of coal sample $\mathrm{M}$ in Figure 4(b), it can be seen that the burst coal sample (after testing) is loose, breaking up as soon as it is touched, and with fracture surfaces showing no clear directionality. It is divided into unit cells by longitudinal and transverse cracks, as shown in Figure 4(b). According to the fact that the energy released in the instantaneous destruction of coal sample cannot be dissipated by vertical through-cracks, and the coal sample 

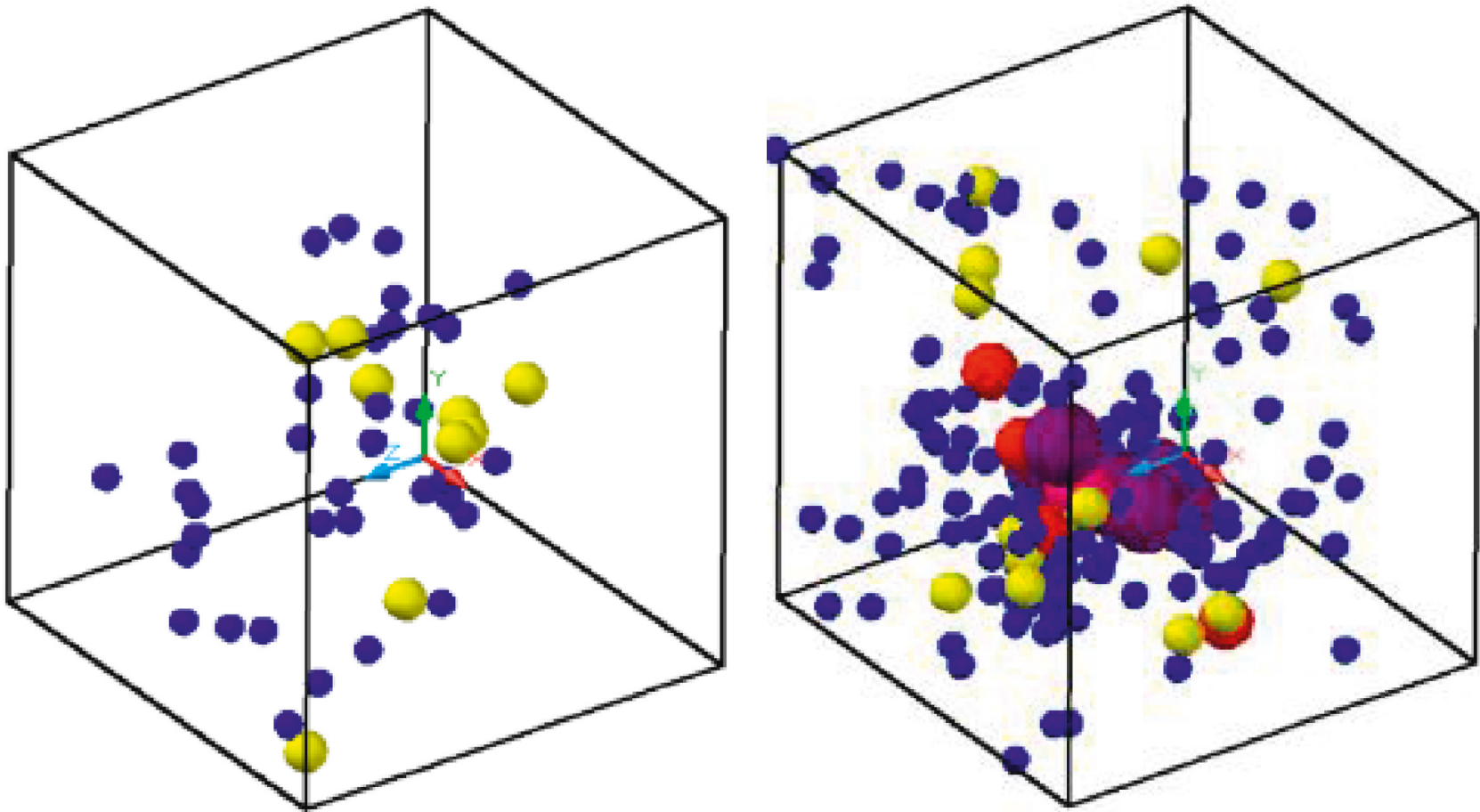

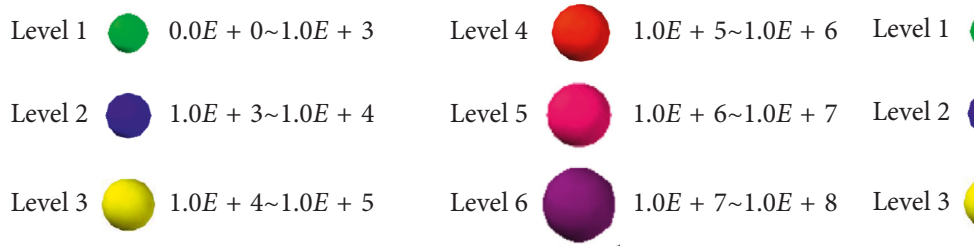

(a)

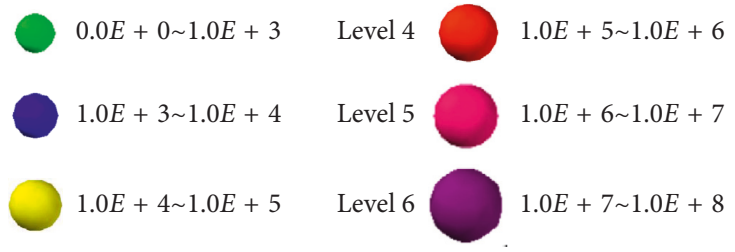

(b)

FIGURE 5: AE event locations of nonbursting and bursting coal samples: (a) nonbursting sample C;(b) bursting sample M; (c) legend.

shows the characteristics of bursting failure. The AE event energy of the burst coal sample is much larger than that of a nonbursting sample, and the maximum energy of AE events is greater than $1.0 \times 107 \mu \mathrm{V} \cdot \mathrm{s}$, as shown in Figure 5(b).

\section{Mechanism and Theoretical Analysis}

4.1. The Stress Equation. At present, the strength calculations of coal samples under the triaxial stress state are mainly based on conditions of equal confining pressure, among which the Mohr-Coulomb criterion and Mogi-Coulomb criterion are the most widely used. The stress path " $Y$-axis loading, $Z$-axis unloading, and $X$-axis displacement" unchanged used in this experiment is significantly different from the stress environment of conventional strength calculation methods. To determine the calculation method of yield stress and peak stress under true-triaxial loading and unloading, the following analysis is carried out.

\subsubsection{Factors Affecting Stress Analysis}

(1) RURLR. The RURLRs under the true-triaxial loading and unloading fluctuate from 0.3 to 3.5 , and the relationship between the RURLR and the stress is shown in Figure 6.
According to Figure 6(a), when the RURLR is 0.5 , the loading lateral peak stress of the sample is $70 \mathrm{MPa}$ and the unloading lateral peak stress is $40 \mathrm{MPa}$; when the RURLR increases to 3 , the peak stress on the loading side decreases to $25 \mathrm{MPa}$ and the peak stress of the unloading side decreases to $1 \mathrm{MPa}$ (the peak stress on coal samples in the loading and unloading side decreases exponentially with increasing RURLR and the yield stress (Figure 6(b)) shows the same characteristics). The peak stress and yield stress are given by

$$
\sigma_{\max }=a * h^{\prime-b}+c,
$$

where $a, b$, and $c$ are constant coefficients and $h^{\prime}$ is the RURLR.

(2) Initial Loading Lateral Stress. Peak stresses and yield stress at the loading and unloading lateral side under different initial loading lateral stresses are shown in Figure 7.

As shown in Figure 7(a), when the initial loading lateral stress is $10 \mathrm{MPa}$, the loading lateral peak stress of the sample is about $60 \mathrm{MPa}$ and the unloading lateral peak stress is $23 \mathrm{MPa}$. When the initial loading stress increases to $40 \mathrm{MPa}$, the loading lateral peak stress reaches $80 \mathrm{MPa}$ and the unloading lateral peak stress reaches $40 \mathrm{MPa}$. The peak stress of the coal samples increases linearly with increasing initial 


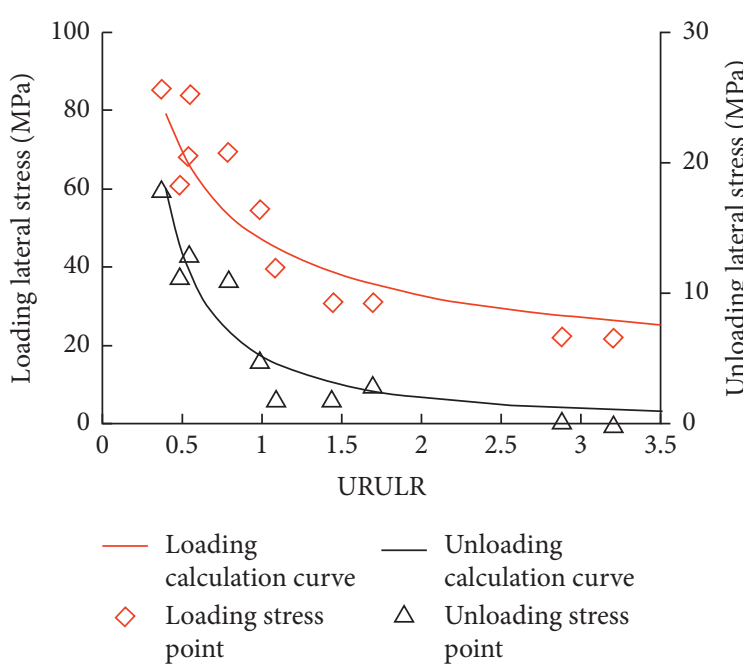

(a)

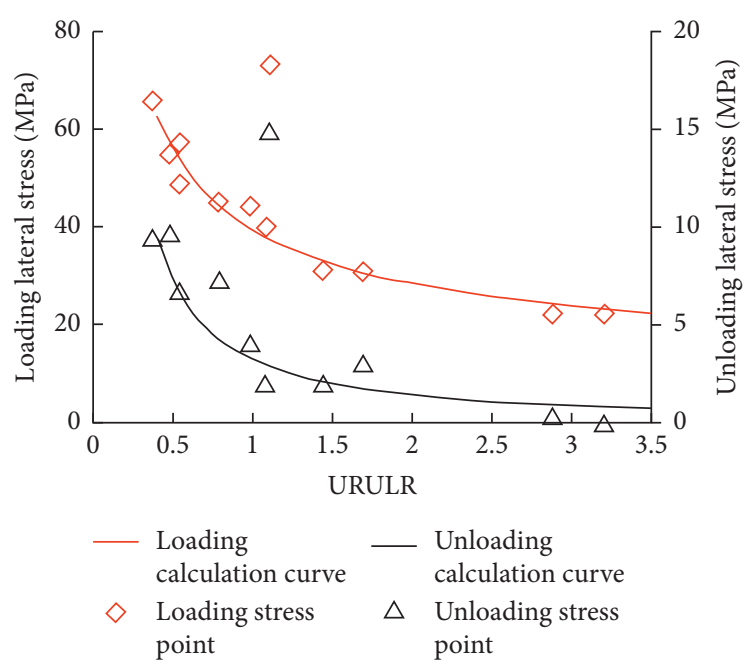

(b)

Figure 6: Stress-RURLR curves. (a) Peak stress (b) Yield stress.

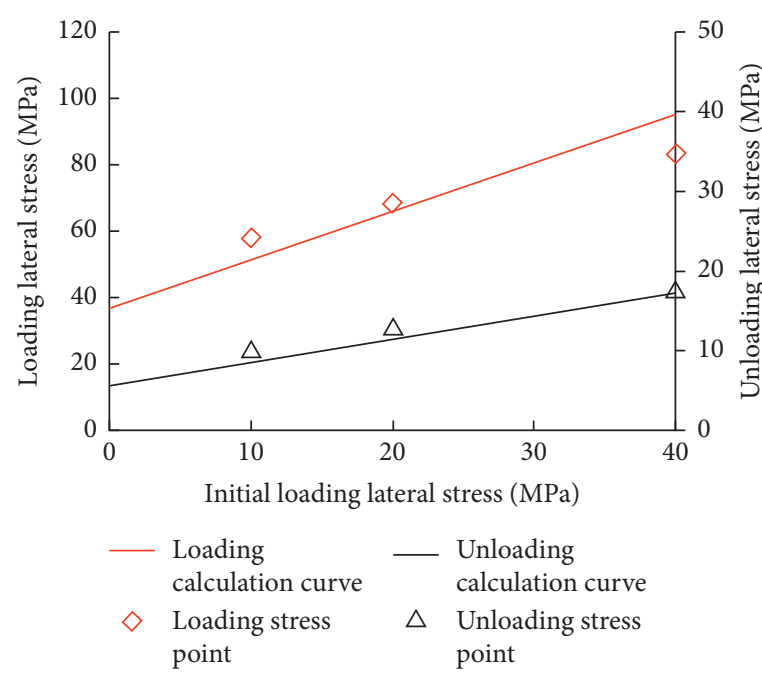

(a)

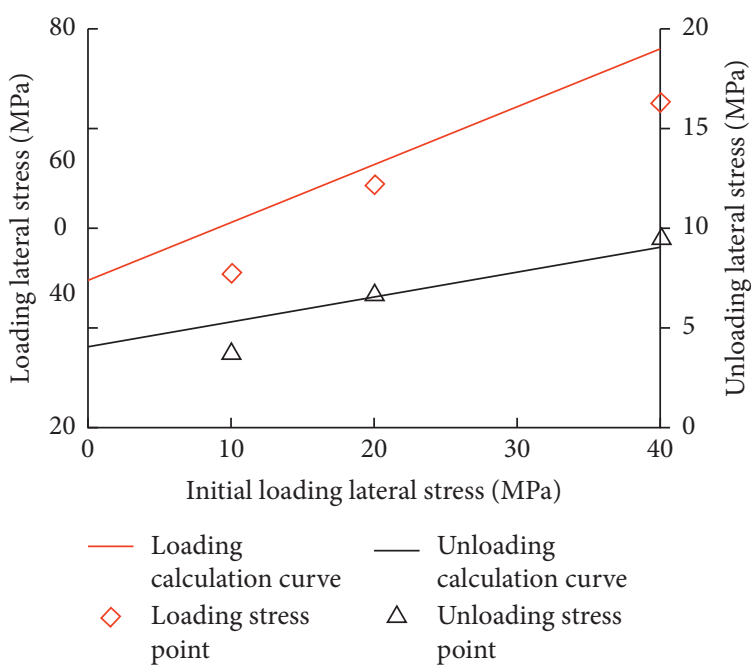

(b)

Figure 7: Stress-initial loading lateral stress plots. (a) Peak stress; (b) Yield stress.

loading lateral stress. The yield stress in Figure 7(b) also shows the same characteristics. The peak stress and yield stress are given by

$$
\sigma_{\max }=a^{\prime} * \sigma_{t}+c^{\prime}
$$

where $a^{\prime}$ and $c^{\prime}$ are constant coefficients and $\sigma_{t}$ is the initial loading lateral stress.

(3) Initial Unloading Lateral Stress. Peak stresses and yield stress at the loading and unloading lateral side under different initial unloading lateral stresses are shown in Figure 8.

As shown in Figure 8(a), when the initial unloading lateral stress is $10 \mathrm{MPa}$, the loading lateral peak stress of the sample is about $60 \mathrm{MPa}$ and the unloading lateral peak stress is $20 \mathrm{MPa}$. When the initial unloading stress increases to $40 \mathrm{MPa}$, the loading lateral peak stress reaches $100 \mathrm{MPa}$ and the unloading lateral peak stress reaches $60 \mathrm{MPa}$. The peak stress on the coal samples increases linearly with the increase of the initial unloading lateral stress. The yield stress in Figure $8(\mathrm{~b})$ also shows the same characteristics. The peak stress and yield stress are given by

$$
\sigma_{\max }=a^{\prime \prime} * \sigma_{c}+c^{\prime \prime},
$$

where $a^{\prime \prime}$ and $c^{\prime \prime}$ are constant coefficients and $\sigma_{c}$ is the initial unloading lateral stress.

(4) Initial Fixed Lateral Stress. Peak stresses and yield stress at the loading and unloading lateral side under different initial fixed lateral stresses are shown in Figure 9.

As shown in Figure 9(a), with the increase of the fixed lateral stress from $10 \mathrm{MPa}$ to $40 \mathrm{MPa}$, the loading lateral stress remains around $60 \mathrm{MPa}$ and the unloading lateral 


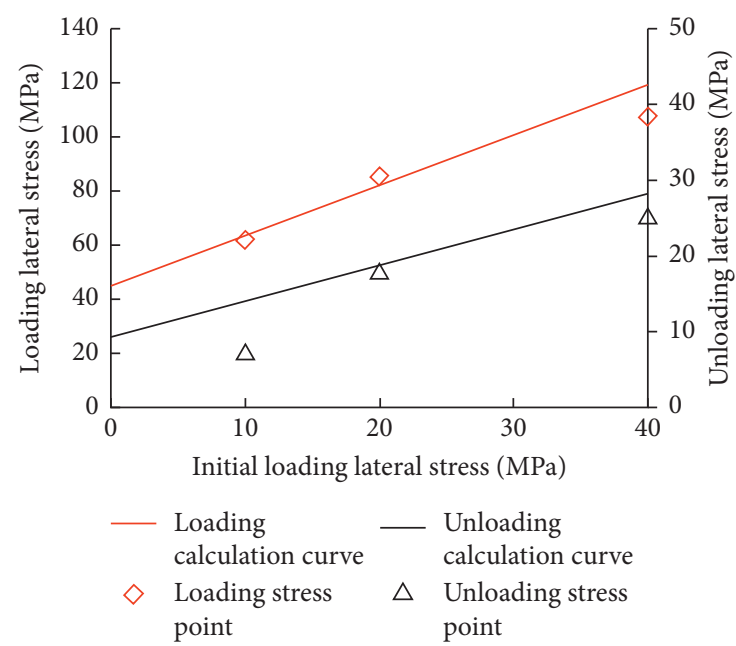

(a)

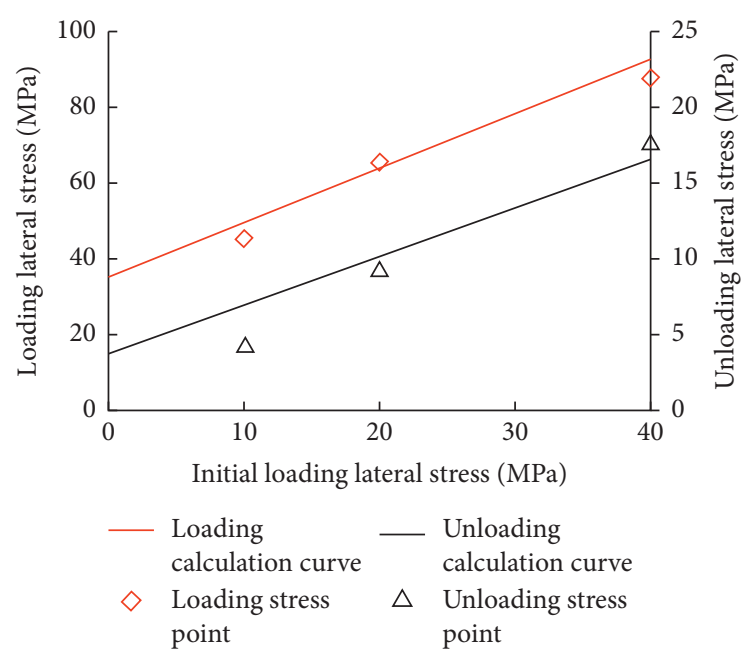

(b)

Figure 8: Stress-initial unloading lateral stress plots. (a) Peak stress; (b) Yield stress.

stress remains around $10 \mathrm{MPa}$. The peak stress on the coal samples is unaffected by the initial fixed lateral stress. The yield stress in Figure 9(b) also shows the same characteristics.

4.1.2. Construction of Stress Equation. According to the analysis of the influencing factors under true-triaxial loading and unloading, the stress equations (1) to (3) can be merged to give

$$
\sigma=\left(A * \sigma_{c}+B * \sigma_{t}\right) * h^{\prime-C}+D .
$$

When $h^{\prime}=+\infty$, the unloading lateral stress disappears instantaneously, which is equivalent to uniaxial compression. For the peak stress on the loading side, $h^{\prime}=+\infty$ is introduced in equation (4) to obtain $D=R_{c}$ (uniaxial compressive strength), giving

$$
\sigma_{\max }=\left(A^{\prime} * \sigma_{c}+B^{\prime} * \sigma_{t}\right) * h^{\prime-C^{\prime}}+R_{c}
$$

Similarly, the loading lateral yield stress can be set to

$$
\sigma_{\max }=\left(A^{\prime \prime} * \sigma_{c}+B^{\prime \prime} * \sigma_{t}\right) * h^{\prime-C^{\prime \prime}}+R_{c}^{\prime} \text {. }
$$

The unloading lateral peak stress can be set to

$$
\sigma_{\max }=\left(A^{\prime \prime \prime} * \sigma_{c}+B^{\prime \prime \prime} * \sigma_{t}\right) * h^{\prime-C^{\prime \prime \prime}} .
$$

The unloading lateral yield stress can be set to

$$
\sigma_{\max }=\left(A^{\prime \prime \prime \prime} * \sigma_{c}+B^{\prime \prime \prime \prime} * \sigma_{t}\right) * h^{\prime-C^{\prime \prime \prime \prime}} .
$$

In formulae (5) to (8), $A^{\prime}, A^{\prime \prime}, A^{\prime \prime \prime}, A^{\prime \prime \prime \prime}, B^{\prime}, B^{\prime \prime}, B^{\prime \prime \prime}, B^{\prime \prime \prime \prime}$, $C^{\prime}, C^{\prime \prime}, C^{\prime \prime \prime}, C^{\prime \prime \prime \prime}$ are constant coefficients; $R_{c}$ is the uniaxial compressive strength and $R_{c}^{\prime}$ is the yield stress during uniaxial compression.

The established peak stress and yield stress equations of the coal samples are fitted with the experimental results. The resulting stress equations are given by equations (9) to (12), and the fitting results are shown in Figure 6.
The loading lateral peak stress equation is as follows:

$$
\sigma_{l \max }=0.98 \cdot\left(\sigma_{c}+\sigma_{t}\right) \cdot h^{\prime-0.66}+8 .
$$

The loading lateral yield stress equation is as follows:

$$
\sigma_{l \text { turn }}=0.82 \cdot\left(\sigma_{c}+\sigma_{t}\right) \cdot h^{\prime-0.58}+6.4 \text {. }
$$

The unloading lateral peak stress equation is as follows:

$$
\sigma_{u \max }=\left(0.1 \cdot \sigma_{c}+0.06 \cdot \sigma_{t}\right) \cdot h^{\prime-1.2} \text {. }
$$

The unloading lateral yield stress equation is as follows

$$
\sigma_{u \text { turn }}=0.13 \cdot\left(\sigma_{c}+\sigma_{t}\right) \cdot h^{\prime-1.33} \text {. }
$$

According to equations (9) to (12), the peak stress-initial stress curves (Figures 7(a) and 8(a)) and yield point stressinitial stress curves are plotted (Figures 7(b) and 8(b)). It can be seen that the resulting curves match the stress applied in the experiment. It can be concluded that the established peak stress equation and the yield stress equation of coal samples under true-triaxial loading and unloading are reasonable.

4.2. Analysis of Energy Evolution. Research has shown that the energy released by tremors is proportional to applied stress and the tremors are closely related to rock burst occurrence $[37,38]$. When the number of mine tremors is large, the energy and frequency cannot directly reflect the characteristics of stress and fracture evolution, and to meet the requirements of quantitative analysis, an energy index cloud is established.

The samples were usually divided into gridded cubes when establishing the energy index nephogram; however, AE events were considered as point sources when calculating source locations. To avoid a lack of fidelity in the results induced by omitting individual AE events, the relationship between the grid spacing $S$ and the statistically smoothed radius $r$ should satisfy $S \leq \sqrt{2} R$. Figure 10 shows a sketch map of the spatial model. Each grid node corresponds to a 


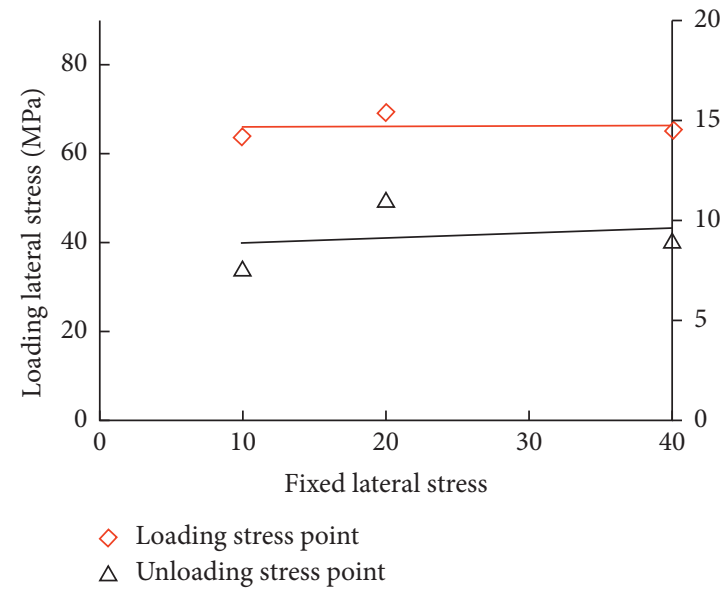

(a)

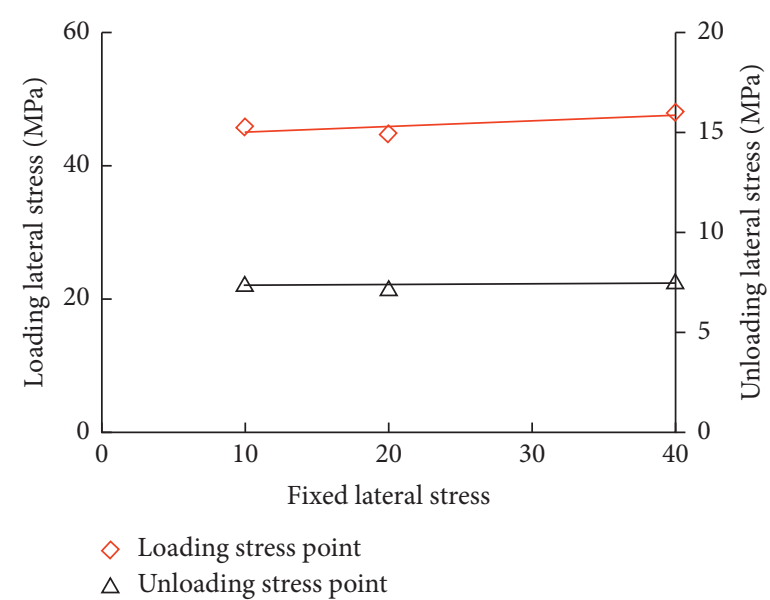

(b)

FIgUre 9: Stress-initial fixed lateral stress data. (a) Peak stress; (b) Yield stress.
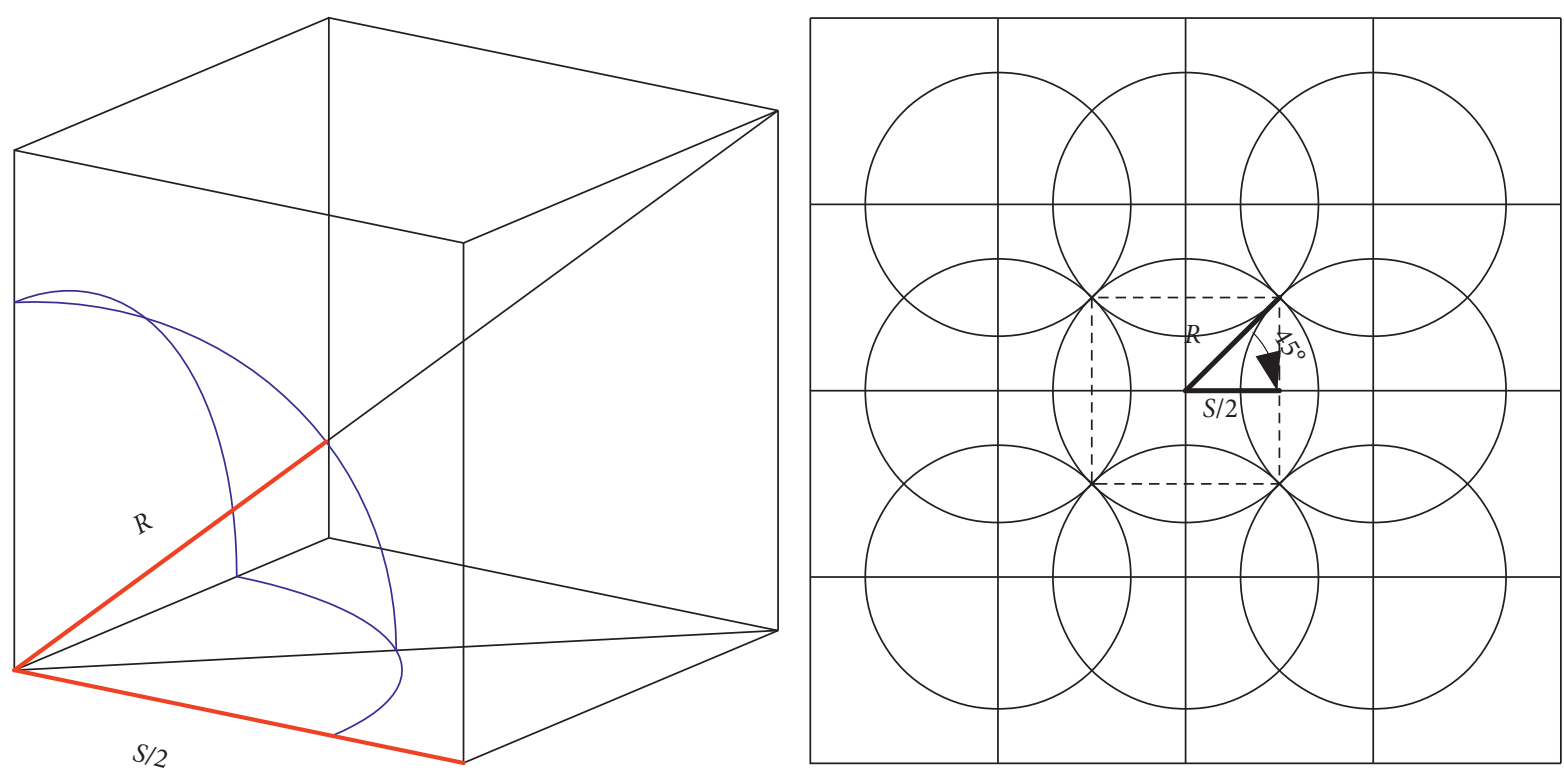

FIGURE 10: Sketch map of the spatial model: $S$ is the grid spacing and $R$ is the statistical smoothed radius.

specific region, and the energy index of a grid node was calculated using (13). Finally, the energy index nephogram can be generated by interpolation. Here, the grid spacing $S$ was set to $5 \mathrm{~mm}$.

$$
e_{i}=\log _{10}\left(\sum E_{j}\right)
$$

where $\sum E_{j}$ is the total energy of the $j^{\text {th }}$ seismic event in the $i^{\text {th }}$ statistical region; $e_{i}$ is the energy index of the $i^{\text {th }}$ statistical region, $\log _{10}(\mathrm{~J})$.

According to the calculation method used to derive the energy index nephogram, the energy index nephograms of sample $M$ are shown in Figures 11(a) to 11(d). These were divided into four stages: loading to the initial triaxial stress stage, loading and unloading stage I, loading and unloading stage II, and a high-speed unloading stage. According to the definition of sample bursting provided in Section 3, the locations of sample burst sources are shown in Figure 11(e).
During loading to the initial triaxial stress process, the high-energy index regions of the coal samples were mainly concentrated within $20 \leq x \leq 35 \mathrm{~mm}, 0 \leq y \leq 30 \mathrm{~mm}$, and $30 \leq z \leq 70 \mathrm{~mm}$ (Figure 11(a)). This is due to the nonuniformity of coal sample structure and the stress is concentrated in a local area under the action of external load. In the first stage of loading and unloading, the original cracks in the coal samples opened and new cracks formed upon unloading; therefore, the ranges of the high-energy index zone became wider than in the previous stage, but their positions remained similar (Figure 11(b)). In the second stage of loading and unloading, the coal sample enters a yielding state: microcracks developed rapidly and formed a penetrating crack network, which resulted in a wider range of high-energy zones than the first two stages (Figure 11(c)).

Upon high-speed unloading, the stress on the coal sample decreased rapidly, and the number of microcracks 

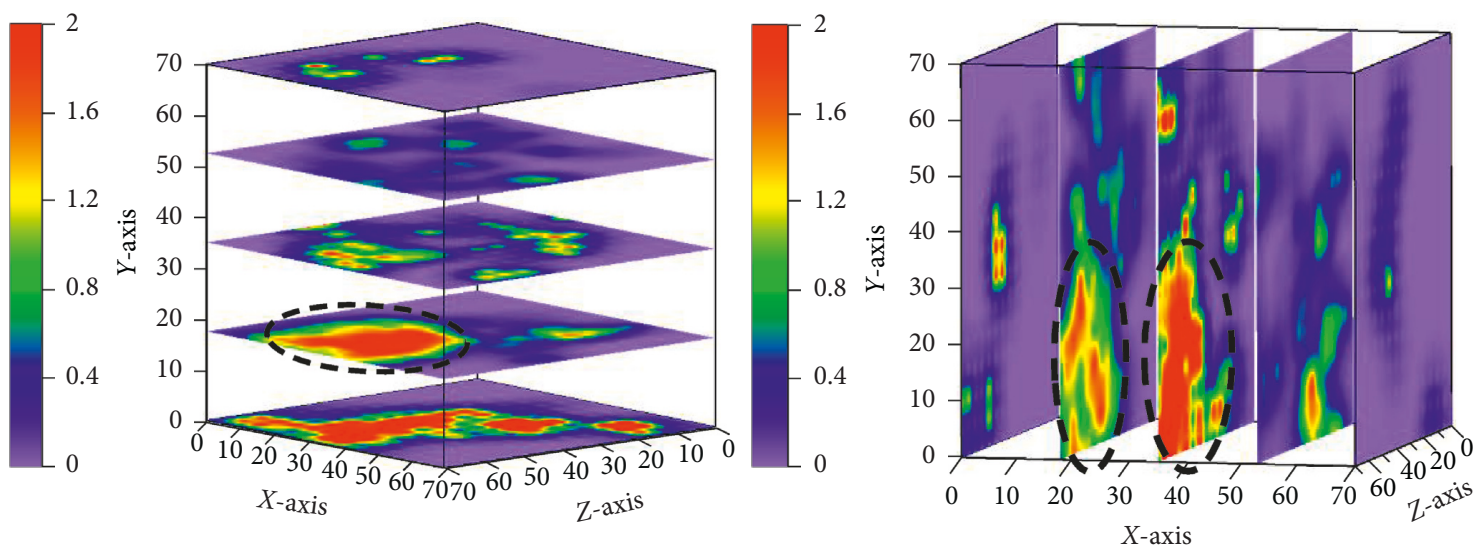

(a)
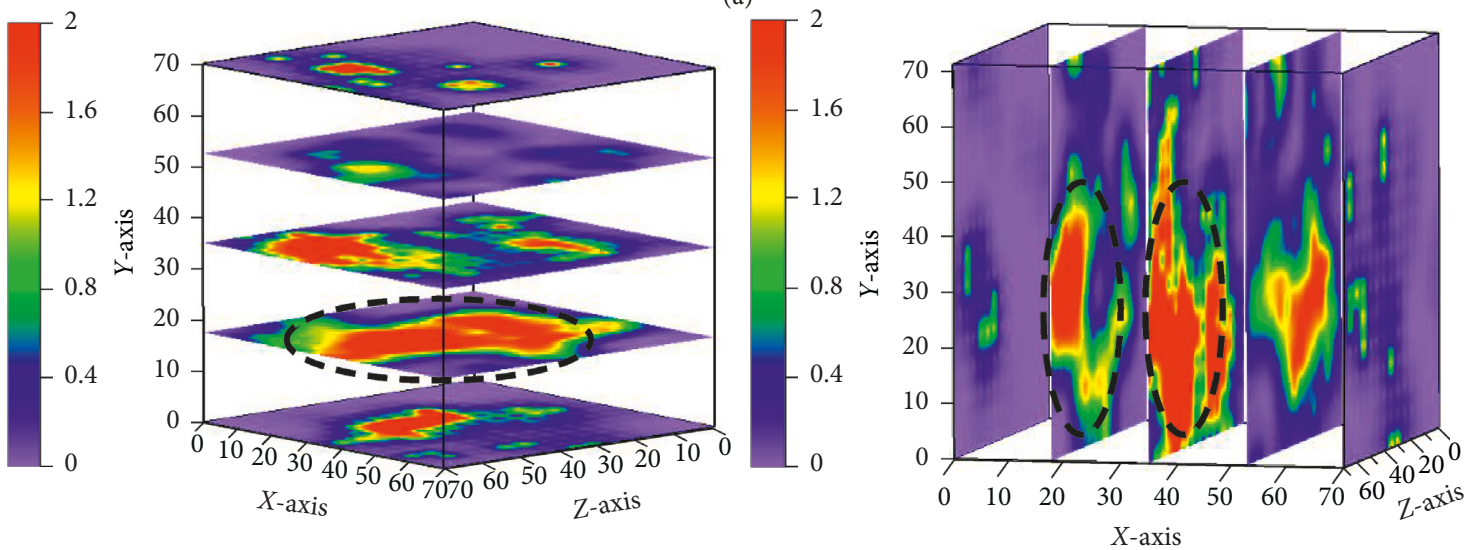

(b)
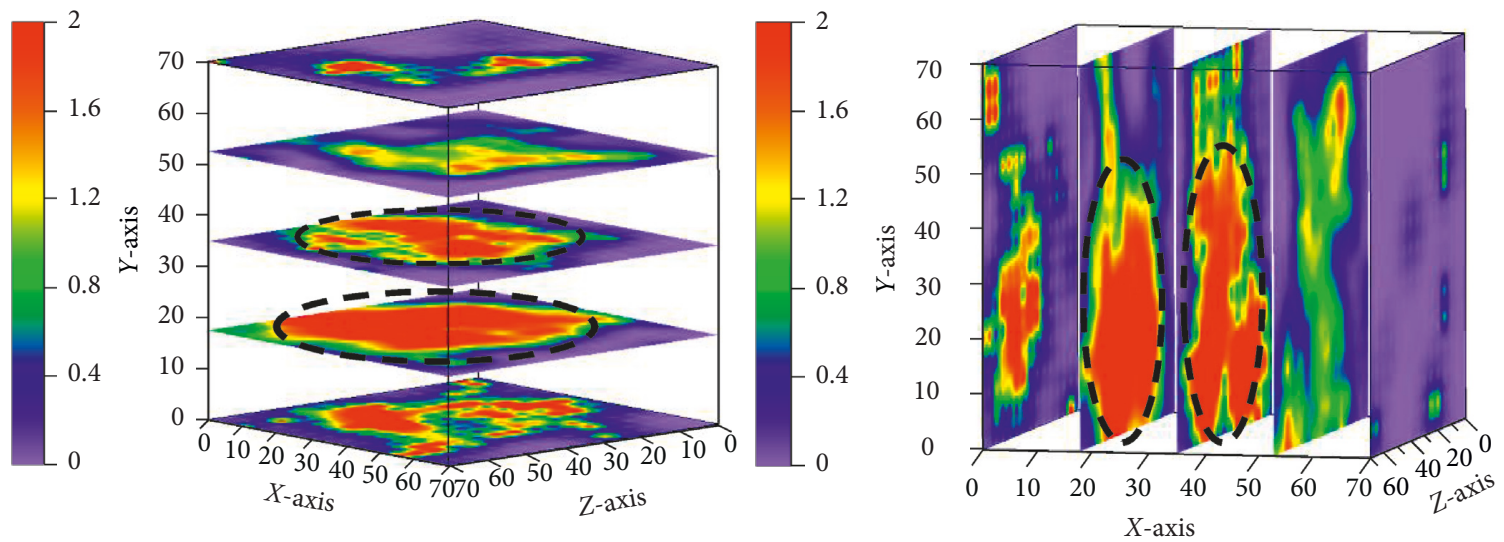

(c)

Figure 11: Continued. 

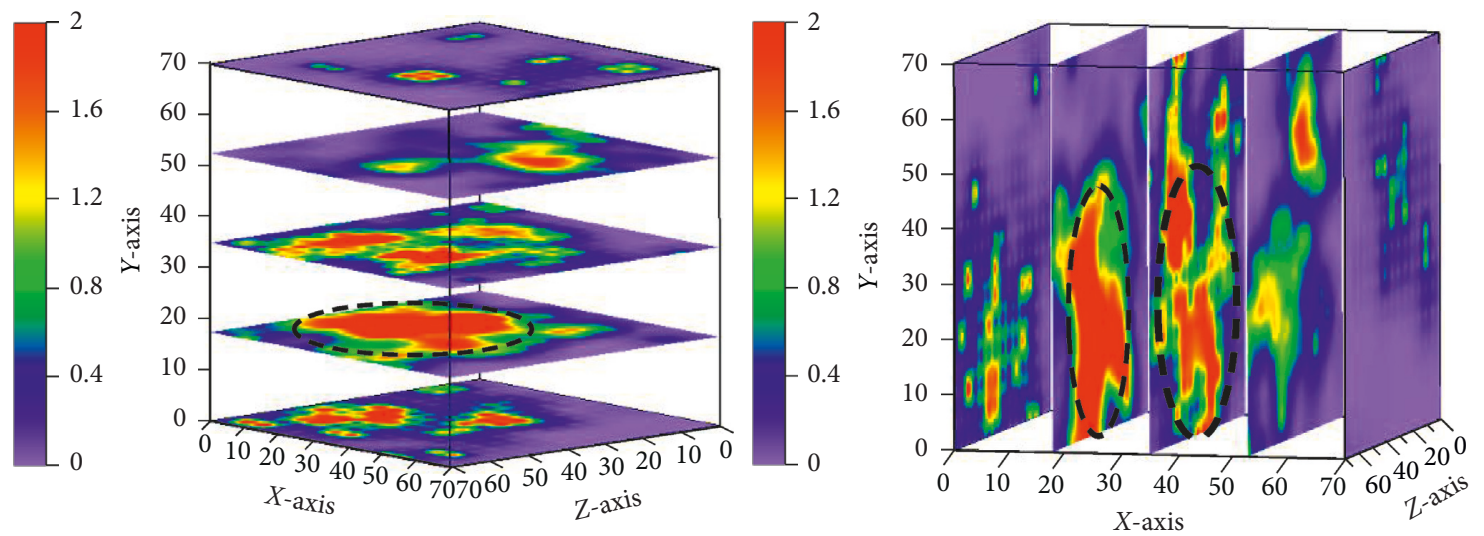

(d)
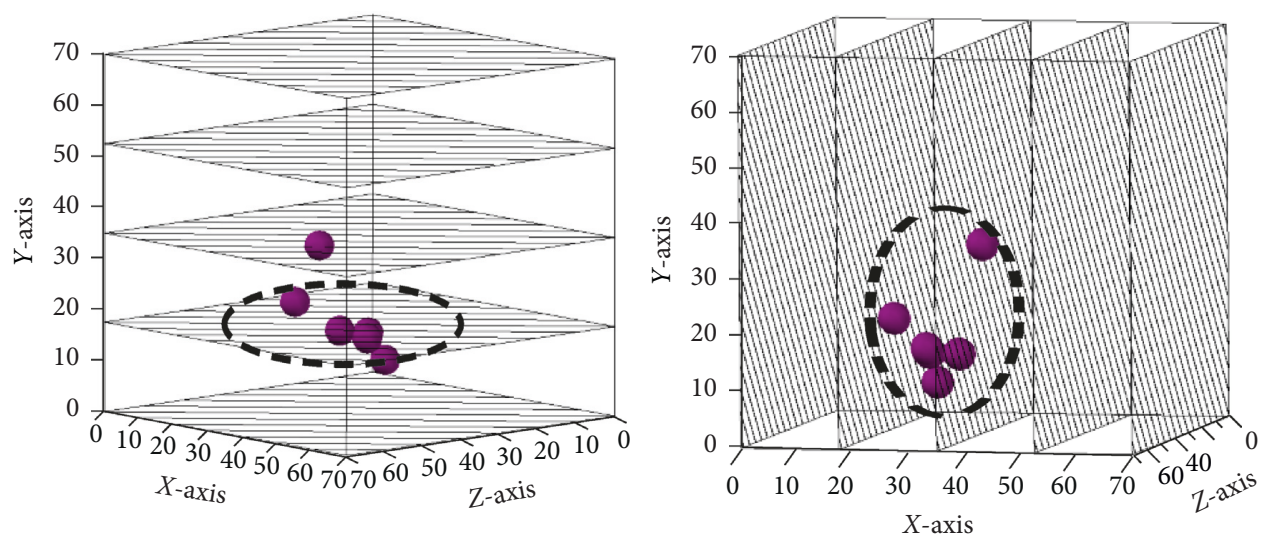

(e)

Figure 11: The energy density nephogram and shock sources at different stages: (a) loading to the triaxial stress stage; (b) true triaxial loading and unloading experimental stage I; (c) true-triaxial loading and unloading experimental stage II; (d) high-speed unloading stage (coal burst experiment); (e) burst source location diagram.

generated was less than that in the first three stages, resulting in a smaller high-energy index zone: however, high-speed unloading promoted the rapid release of accumulated energy from the first three stages, forming a shock source located in the high-energy region (Figure 11(e)).

It can be concluded that during the initial threedimensional stress stage and the first and second stages of loading and unloading, energy gradually accumulated and the high-energy region gradually expanded, but its location always lies within a fixed region. When subjected to high-speed unloading, the accumulated energy in this area was released rapidly, and the coal samples were severely damaged, thus forming the source of a burst.

\section{Conclusion}

(1) The prepeak stress-time curve of the coal samples under true triaxial loading and unloading could be divided into two distinct stages: in the first stage, the stress on the unloading side decreased gradually, and the loading lateral stress gradually increased. In this stage, the acoustic emission signal was weak and the coal body was in an elastic state; in the second stage, the rates of stress reduction and stress increase on the unloading side are lower than those in stage one. The acoustic emission signals were enhanced, and the coal body exhibited dilatant plastic yield. There was an inflection point (yield point) between the second stage and the first stage.

(2) The yield stress and peak stress of coal samples were linearly, and positively, correlated with the initial loading lateral stress and the initial unloading lateral stress, which were unaffected by the fixed lateral stress and exponentially decreased with RURLR. Thus, the yield stress and peak stress equations applicable to such coal samples under true triaxial loading and unloading were established.

(3) According to experimental evidence, the high unloading rate and the high initial stress are precursors to a coal sample bursting. The nonbursting coal samples underwent spallation failure, and the normal direction of the fracture surface was parallel to the unloading direction. The energy of the acoustic emission events was less than $1 \times 10^{5} \mu \mathrm{V} \cdot \mathrm{s}$; the burst coal samples showed all of the characteristics of burst failure, and the energy of acoustic emission events at failure exceeded $1 \times 10^{7} \mu \mathrm{V} \cdot \mathrm{s}$. 
(4) During the initial three-dimensional stress stage and the first and second stages of loading and unloading, the high-energy area expanded, but its location was always fixed to within a certain area. When subjected to high-speed unloading, the accumulated energy in this area was released rapidly, and the coal samples were severely damaged, thus forming the source of a burst.

\section{Data Availability}

The data used to support the findings of this study are included within the article.

\section{Conflicts of Interest}

The authors declare that there are no conflicts of interest regarding the publication of this paper.

\section{Acknowledgments}

The authors extend special thanks to the team at Hua-ting coal mine, who provided the coal body. The authors gratefully acknowledge the financial support for this work provided by the State Key Research Development Program of China (Grant no. 2018YFC0604705), Projects (PAPD) supported by the Priority Academic Program Development of Jiangsu Higher Education Institutions, and the National Natural Science Foundation of China (Grant nos. 51874292 and 51974302).

\section{References}

[1] A. T. Iannacchione and S. C. Tadolini, "Occurrence, predication, and control of coal burst events in the U.S.," International Journal of Mining Science and Technology, vol. 26, no. 1, pp. 39-46, 2016.

[2] C. Mark and M. Gauna, "Evaluating the risk of coal bursts in underground coal mines," International Journal of Mining Science and Technology, vol. 26, no. 1, pp. 47-52, 2016.

[3] G. A. Zhu, L. M. Dou, C. B. Wang, J. Li, W. Cai, and Z.-W. Ding, "Numerical investigations on evolution characteristics of overlying strata and distribution of static and dynamic load in an island coal panel," Arabian Journal of Geoscience, vol. 10, no. 24, p. 549, 2017.

[4] T. B. Zhao, Y. C. Yin, and Y. L. Tan, "Safe mining and new prediction model in coal seam with coal burst induced by roof," Disaster Advances, vol. 5, no. 4, pp. 961-965, 2012.

[5] Y. D. Jiang, Y. S. Pan, F. X. Jiang, L.-M. Dou, and Y. Ju, "State of the art review on mechanism and prevention of coal bumps in China," Journal of China Coal Society, vol. 39, no. 2, pp. 205-213, 2014.

[6] Z.-L. Li, L.-M. Dou, W. Cai, G.-F. Wang, Y.-L. Ding, and Y. Kong, "Mechanical analysis of static stress within faultpillars based on a voussoir beam structure," Rock Mechanics and Rock Engineering, vol. 49, no. 3, pp. 1097-1105, 2016.

[7] J. He, L.-M. Dou, Z.-L. Mu, A.-Y. Cao, and S.-Y. Gong, "Numerical simulation study on hard-thick roof inducing rock burst in coal mine," Journal of Central South University, vol. 23, no. 9, pp. 2314-2320, 2016.

[8] H. P. Xie, H. W. Zhou, J. F. Liu et al., "Mining-induced mechanical behavior in coal seams under different mining layouts," Journal of the China Coal Society, vol. 36, no. 7, pp. 1067-1074, 2011.

[9] H. P. Xie, Z. T. Zhang, F. Gao et al., "Stress-fracture-seepage field behavior of coal under different mining layouts," Journal of the China Coal Society, vol. 41, no. 10, pp. 2405-2417, 2016.

[10] J. J. Wang, M. N. Liu, F. X. Jian, and H.-J. Chai, "Mechanical behaviors of a sandstone and mudstone under loading and unloading conditions," Environmental Earth Sciences, vol. 78, no. 1, p. 30, 2019.

[11] X. Chen, C.-A. Tang, J. Yu, J.-F. Zhou, and Y.-Y. Cai, "Experimental investigation on deformation characteristics and permeability evolution of rock under confining pressure unloading conditions," Journal of Central South University, vol. 25, no. 8, pp. 1987-2001, 2018.

[12] B. Dai, G.-Y. Zhao, H. Konietzky, and P. L. P. Wasantha, "Experimental investigation on damage evolution behaviour of a granitic rock under loading and unloading," Journal of Central South University, vol. 25, no. 5, pp. 1213-1225, 2018.

[13] D. Huang, R. Q. Huang, Y. X. Zhang et al., "Characteristics of brittle failure and stress drop under triaxial loading and unloading," Journal of Civil, Architectural and Environmental Engineering, vol. 33, no. 2, pp. 1-6, 2011.

[14] G. S. Su, J. Q. Jiang, S. B. Zhai, and G. Zhang, "Influence of tunnel axis stress on strainburst: an experimental study," Rock Mechanics and Rock Engineering, vol. 50, no. 6, pp. 1551-1567, 2017.

[15] S. Qiu, X. Feng, C. Zhang, and T. Xiang, "Estimation of rockburst wall-rock velocity invoked by slab flexure sources in deep tunnels," Canadian Geotechnical Journal, vol. 51, no. 5, pp. 520-539, 2014.

[16] D. Li, Z. Sun, T. Xie, X. Li, and P. G. Ranjith, "Energy evolution characteristics of hard rock during triaxial failure with different loading and unloading paths," Engineering Geology, vol. 228, pp. 270-281, 2017.

[17] Y. T. Guo, C. H. Yang, J. J. Fu et al., "Experimental research on mechanical characteristics of salt rock under tri-axial unloading test," Rock and Soil Mechanics, vol. 33, no. 3, pp. 725-732, 2012.

[18] G. Su, X. Feng, J. Wang, J. Jiang, and L. Hu, "Experimental study of remotely triggered rockburst induced by a tunnel axial dynamic disturbance under true-triaxial conditions," Rock Mechanics and Rock Engineering, vol. 50, no. 8, pp. 2207-2226, 2017.

[19] G. Z. Yin, Y. B. Liu, M. H. Li, B. Deng, C. Liu, and J. Lu, "Influence of true triaxial loading-unloading stress paths on mechanical property and permeability of coal," Journal of China Coal Society, vol. 43, no. 1, pp. 131-136, 2018.

[20] Z. Chen, G. Su, J. W. Ju, and J. Jiang, "Experimental study on energy dissipation of fragments during rockburst," Bulletin of Engineering Geology and the Environment, vol. 78, no. 7, pp. 5369-5386, 2019.

[21] X.-T. Feng, R. Kong, X. Zhang, and C. Yang, "Experimental study of failure differences in hard rock under true triaxial compression," Rock Mechanics and Rock Engineering, vol. 52, no. 7, pp. 2109-2122, 2019.

[22] Y. Liu, G. Yin, M. Li et al., “Anisotropic mechanical properties and the permeability evolution of cubic coal under true triaxial stress paths," Rock Mechanics and Rock Engineering, vol. 52, no. 8, pp. 2505-2521, 2019.

[23] G.-A. Zhu, L.-M. Dou, C.-B. Wang, Z.-W. Ding, Z.-J. Feng, and F. Xue, "Experimental study of rock burst in coal samples under overstress and true-triaxial unloading through passive velocity tomography," Safety Science, vol. 117, pp. 388-403, 2019. 
[24] W. S. Pettitt, "Acoustic emission source studies of microcracking in rock," Dissertation, Keele University, Keele, UK, 1998.

[25] S.-H. Chang and C.-I. Lee, "Estimation of cracking and damage mechanisms in rock under triaxial compression by moment tensor analysis of acoustic emission," International Journal of Rock Mechanics and Mining Sciences, vol. 41, no. 7, pp. 1069-1086, 2004.

[26] M. Cai, P. K. Kaiser, Y. Tasaka, T. Maejima, H. Morioka, and M. Minami, "Generalized crack initiation and crack damage stress thresholds of brittle rock masses near underground excavations," International Journal of Rock Mechanics and Mining Sciences, vol. 41, no. 5, pp. 833-847, 2004.

[27] H. Alkan, Y. Cinar, and G. Pusch, "Rock salt dilatancy boundary from combined acoustic emission and triaxial compression tests," International Journal of Rock Mechanics and Mining Sciences, vol. 44, no. 1, pp. 108-119, 2007.

[28] F. Amann, E. A. Button, K. F. Evans, V. S. Gischig, and M. Blümel, "Experimental study of the brittle behavior of clay shale in rapid unconfined compression," Rock Mechanics and Rock Engineering, vol. 44, no. 4, pp. 415-430, 2011.

[29] J. T. Chen and G. S. Su, "True triaxial experimental study on hard rock under high geo-stress condition based on excavation and support," International Conference on Mechanic Automation and Control Engineering, pp. 1465-1467, 2010.

[30] M. C. He, J. L. Miao, and J. L. Feng, "Rock burst process of limestone and its acoustic emission characteristics under truetriaxial unloading conditions," International Journal of Rock Mechanics and Mining Sciences, vol. 47, no. 2, pp. 286-298, 2010.

[31] M. C. He, X. N. Jia, M. Coil, E. Livi, and L. Sousa, "Experimental study of rockbursts in underground quarrying of Carrara marble," International Journal of Rock Mechanics and Mining Sciences, vol. 52, pp. 1-8, 2012.

[32] M. He, L. R. e Sousa, T. Miranda, and G. Zhu, "Rockburst laboratory tests database-application of data mining techniques," Engineering Geology, vol. 185, pp. 116-130, 2015.

[33] X. G. Zhao, J. Wang, M. Cai et al., "Influence of unloading rate on the strainburst characteristics of Beishan granite under true-triaxial unloading conditions," Rock Mechanics and Rock Engineering, vol. 47, no. 2, pp. 467-483, 2014.

[34] G. Su, Y. Shi, X. Feng, J. Jiang, J. Zhang, and Q. Jiang, “Truetriaxial experimental study of the evolutionary features of the acoustic emissions and sounds of rockburst processes," Rock Mechanics and Rock Engineering, vol. 51, no. 2, pp. 375-389, 2018.

[35] Q. S. Bai, M. Tibbo, M. H. B. Nasseri, and R. P. Young, "True triaxial experimental investigation of rock response around the mine-by tunnel under an in situ 3D stress path," Rock Mechanics and Rock Engineering, vol. 52, no. 10, pp. 1-16, 2019.

[36] J. He, Research of mining dynamic loading effect and its induced coal burst in coal mine, Ph.D. thesis, China University of Mining and Technology, Xuzhou, China, 2013.

[37] M. J. Friedel, D. F. Scott, and T. J. Williams, "Temporal imaging of mine-induced stress change using seismic tomography," Engineering Geology, vol. 46, no. 2, pp. 131-141, 1997.

[38] W. Shen, L. M. Dou, H. He, and G.-A. Zhu, "Rock burst assessment in multi-seam mining: a case study," Arabian Journal of Geosciences, vol. 10, p. 196, 2017. 


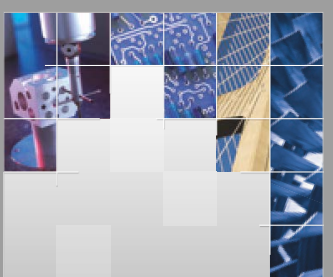

\section{Enfincering}
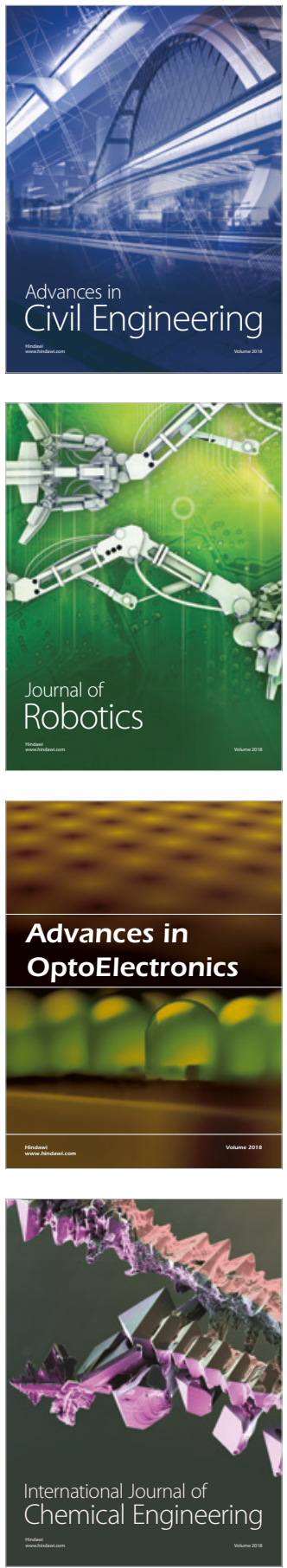

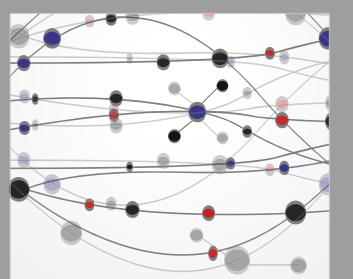

\section{Rotating \\ Machinery}

The Scientific World Journal

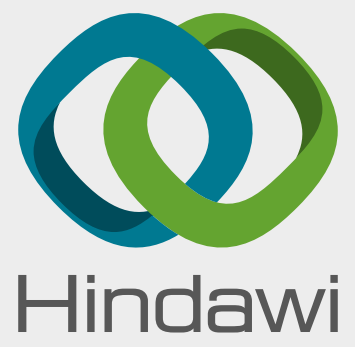

Submit your manuscripts at

www.hindawi.com
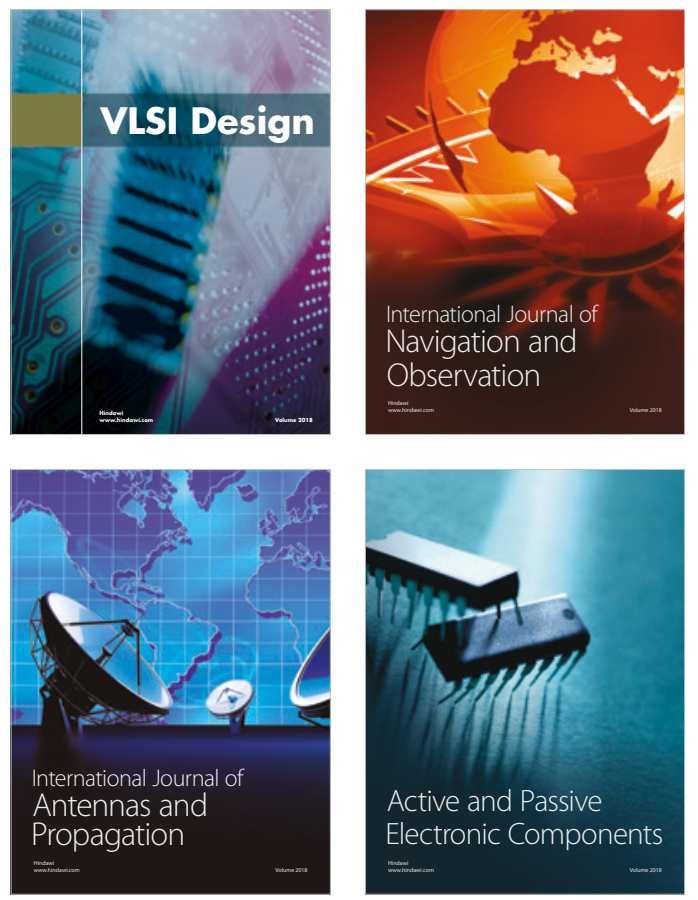
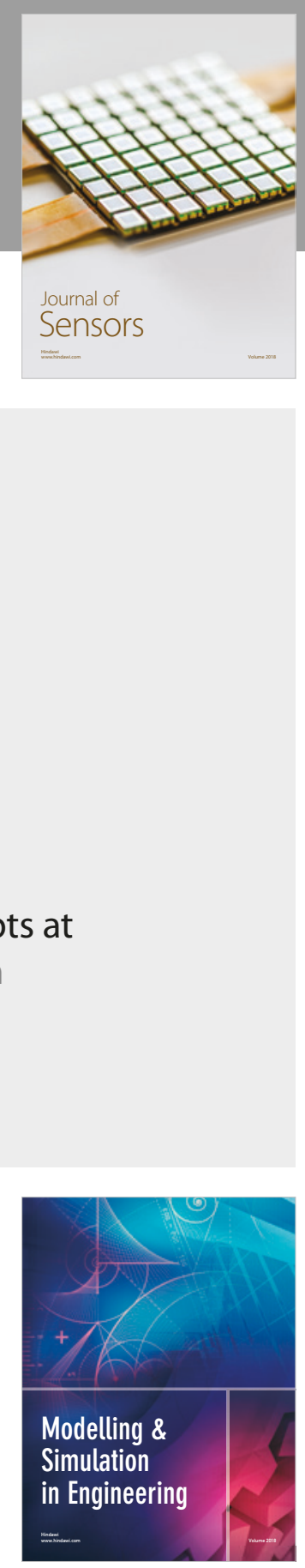

\section{Advances \\ Multimedia}
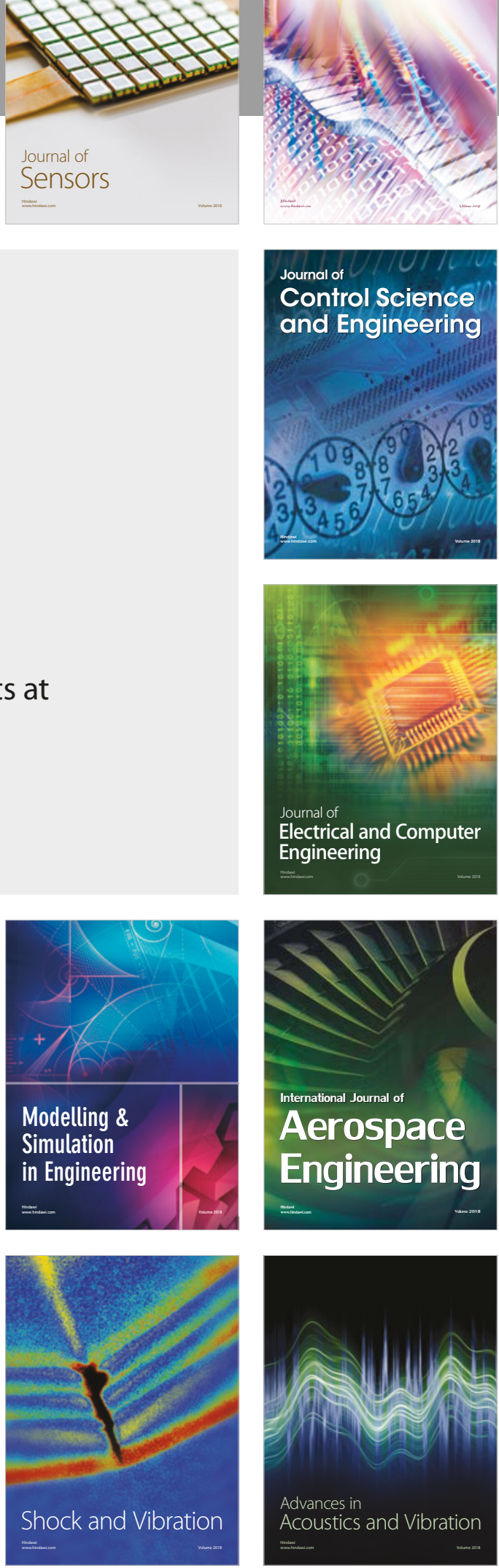